Griffiths, T. A. ${ }^{*}$, Habler, G. ${ }^{1}$, Rhede, D. ${ }^{2}$, Wirth, R. $^{2}$, Ram, F. ${ }^{3} \&$ Abart, R. ${ }^{1}$

\title{
Localization of submicron inclusion re-equilibration at healed fractures in host garnet
}

${ }^{1}$ Department of Lithospheric Research, Center for Earth Sciences, University of Vienna, Althanstrasse 14, 1090 Vienna, Austria.

${ }^{2}$ GFZ German Research Center for Earth Sciences, Telegrafenberg, 14473 Potsdam, Germany.

${ }^{3}$ Max-Planck-Institut für Eisenforschung (MPIE) GmbH, Department of Microstructure Physics and Alloy

Design, Max-Planck-Strasse 1, 40237 Düsseldorf, Germany

*th.griffiths@univie.ac.at, Tel.: +43-1-4277-53462, Fax: +43-1-4277-9534 


\begin{abstract}
Microstructures in Permian inclusion-bearing meta-pegmatite garnets from the Koralpe (Eastern Alps, Austria) reveal re-equilibration by coarsening of abundant submicron-sized inclusions ( $1 \mu \mathrm{m}-$ $2 \mathrm{~nm}$ diameter) at the site of healed brittle cracks. The microstructures developed during Cretaceous eclogite facies deformation and the related overprinting of the host-inclusion system. Trails of coarsened inclusions $(1-10 \mu \mathrm{m}$ diameter) crosscut the garnet, defining traces of former fractures with occasional en-echelon overlaps. Trails are flanked by $10-100 \mu \mathrm{m}$ wide 'bleaching zones' characterized by the absence of $\leq 1 \mu \mathrm{m}$ sized inclusions in optical and SE images. FEG-microprobe data show that trails and bleaching zones can form isochemically, although some trails exhibit nonisochemical coarsening. Cross correlation EBSD reveals subtle garnet lattice rotation of up to $0.45^{\circ}$ around consistent misorientation axes, spatially correlated with bleaching zones. Elevated dislocation density within these zones is confirmed by TEM observations. Brittle fracture enhanced diffusion rates in the lattice adjacent to crack planes, priming these areas to behave differently to the bulk of the garnet during Cretaceous metamorphism and facilitating localized coarsening of inclusions. The preferred mechanism for this is increased dislocation density near former cracks, with the dislocations interpreted as a plastic wake originating from crystal plastic deformation at the crack tip. This partially closed host-inclusion system clearly records the influence of deformation mechanisms on re-equilibration and contributes to a wider understanding of the interaction between deformation and chemical reaction during metamorphism.
\end{abstract}




\section{Introduction}

Mineral inclusions are a key tool in the interpretation of complex geological histories. Geological information can be encoded (Danyushevsky et al. 2002; Hwang et al. 2007) or lost (Cooke et al. 2000) by re-equilibration of an inclusion, either as an equilibrium is reached with a new host, or as a previous host-inclusion assemblage strives to attain a new equilibrium under altered conditions. Assigning a chemical or microstructural reequilibration signature to a specific stage of a rock's evolution requires information on the potential mechanisms of re-equilibration.

Deformation can be both a facilitator and a consequence of inclusion re-equilibration. Strain can create fast diffusion pathways in the form of brittle cracks (Whitney 1991) or dislocations and (sub)grain boundaries (Ruoff and Balluffi 1963; Keller et al. 2006; Konrad-Schmolke et al. 2007). Inclusions can localize deformation (Timms et al. 2012), and volume changes can induce deformation of the host (Carstens 1971; Whitney et al. 2000).

Fracturing and re-equilibration of garnet and inclusions under new metamorphic conditions has been widely documented (Hames and Menard 1993; Erambert and Austrheim 1993; Whitney et al. 1996; KonradSchmolke et al. 2007). Usually this is associated with open system behavior, although Røhr et al. (2007) also linked closed system re-equilibration to garnet deformation. One mechanism that could connect re-equilibration and deformation is the effect of dislocation density on diffusion rates (Chakraborty and Ganguly 1991). Following TEM observations in deformed garnets (Ji and Martignole 1994; Voegelé et al. 1998a; Voegelé et al. 1998b), evidence for crystal plastic deformation in garnet has grown steadily (Prior et al. 2002; Storey and Prior 2005; Vollbrecht et al. 2006; Massey et al. 2011; Martelat et al. 2012), but has so far only been linked to inclusion re-equilibration in one case (Bestmann et al. 2008).

This study examines unusual inclusion-rich metapegmatite garnets known to have undergone both brittle and ductile deformation at conditions different to those under which the initial host-inclusion equilibrium was established (Habler et al. 2007; Bestmann et al. 2008). Inclusion trail microstructures provide an opportunity to observe the spatial extent of re-equilibration and to gain insight into the mechanisms governing the interaction of deformation and re-equilibration in this system. Such interactions are an essential feature of many forms of metamorphism (de Ronde et al. 2005; Terry and Heidelbach 2006). It is found that brittle 
fracture affects diffusion in the intact crystal lattice adjacent to crack planes. This affects the rate and location of inclusion re-equilibration during metamorphic overprinting.

\section{Geological setting}

The sample investigated in this paper, 04T26K, stems from the locality Wirtbartl, in the Koralpe, Austria (geographic coordinates: 5177709 N, 504737 E; UTM zone 33N, geodetic datum: WGS84). The rock unit is part of the Saualpe-Koralpe crystalline basement complex, a member of the Austroalpine basement units in the Eastern Alps (Schmid et al. 2004). The complex comprises mainly poly-metamorphic siliciclastic metasediments with rare marbles and intercalated calc-silicates, amphibolites, eclogites and metapegmatites. These rocks experienced a predominant eclogite-facies tectono-metamorphic imprint during the upper Cretaceous (Thöni and Miller 1996), which overprinted Permian low-pressure assemblages. Permian metamorphic conditions have been estimated at $600^{\circ} \mathrm{C} / 0.4$ GPa by Habler and Thöni (2001) and $650^{\circ} \mathrm{C} / 0.6$ 0.65 GPa by Tenczer et al. (2006). Widespread Al-rich pegmatites give undisturbed Permian garnet Sm-Nd ages ranging from 285 to $225 \mathrm{Ma}$ (Thöni et al. 2008; Thöni and Miller 2009). Pegmatites are interpreted as a product of local melting of siliciclastic (meta)sedimentary protoliths (Thöni and Miller 2000; Habler et al. 2007; Thöni et al. 2008)

The Koralpe nappes underwent major deformation during the eclogite facies eo-Alpine tectonometamorphic event. The Saualpe-Koralpe complex was subducted and then rapidly exhumed during continentcontinent collision of the European and Adriatic plates (Stüwe and Schuster 2010), reaching maximum burial depth between 95 and $90 \mathrm{Ma}$ ago (Thöni 2006) and returning to below $300^{\circ} \mathrm{C}$ by 70 - 80 Ma ago (Morauf 1982; Thöni 2002). No P-T data has been obtained directly from the sampling area, but peak conditions calculated from different eclogites in the Koralpe are $600-650^{\circ} \mathrm{C} / 1.8-2 \mathrm{GPa}$ (Miller and Thöni 1997), $630-730^{\circ} \mathrm{C}$ with a fixed P of 2.4 GPa (Miller et al. 2005; Miller et al. 2007) and $700-750^{\circ} \mathrm{C} / 1.5-1.6 \mathrm{GPa}$ (Gregurek et al. 1997). P-T conditions estimated from metapelites are $700 \pm 50^{\circ} \mathrm{C} / 1.4-1.6 \mathrm{GPa}$ (Gregurek et al. 1997) and $700 \pm 68^{\circ} \mathrm{C}$ $/ 1.5 \pm 0.15 \mathrm{GPa}$ to $600 \pm 63^{\circ} \mathrm{C} / 1.0 \pm 0.15 \mathrm{GPa}$ (Tenczer and Stüwe 2003). P-T variations are understood as representing either different tectonic units within the Koralpe or the equilibration of different lithologies at different stages of a P-T path.

The Wirtbartl locality consists of predominant Al-rich metapelites with large kyanite paramorphs after andalusite, intercalated with peraluminous metapegmatites containing the garnets examined in this study (Habler et al. 2007; Thöni et al. 2008; Bestmann et al. 2008). These garnets grew entirely during the Permian and are 
completely magmatic in origin. The only indicators of Cretaceous overgrowth are rare, very thin ( $\leq 50 \mu \mathrm{m}$ wide) Ca-rich regions at the very rim of the garnet, in contact with plagioclase (Habler et al. 2007, Bestmann et al. 2008).

\section{Methods}

\section{Sample preparation}

Thin sections were prepared first by mechanical and finally by chemo-mechanical polishing. The latter was performed on an active-head rotary polishing system using an alkaline colloidal silica suspension and a polyurethane plate to ensure a defect-free surface for electron backscattered diffraction (EBSD) analysis. Thin sections were carbon-coated to establish electrical conductivity. For EBSD measurements a thin coating was achieved using a single carbon thread at high vacuum $(<1 * 10-5$ mbar chamber pressure).

Field emission electron microprobe analysis

All chemical analyses were carried out on a JEOL JXA 8500F thermal field emission gun (FEG) electron microprobe in wavelength dispersive mode at the GFZ Potsdam, Germany. Chemical compositions of optically clear garnet were collected with a focused beam at 15 and $20 \mathrm{kV}$ accelerating voltage at a beam current of 20 and $10 \mathrm{nA}$ respectively (table 2). Standards for all voltages were well-characterized natural and synthetic materials. The raw intensity data were corrected with the Armstrong-CITZAF on-line correction program (Armstrong 1995). The measured compositions of garnet at higher accelerating voltages were used as internal standards for Fe, Mn, Si and Al measurements at lower accelerating voltages. Most garnet points and all phosphates were measured with a focused beam at an accelerating voltage of $6 \mathrm{kV}$ (beam currents of 20 and 10 nA, specified in tables $2 \& 3$ ) to achieve submicron-sized excitation volumes. Ti phases were measured at an accelerating voltage of $10 \mathrm{kV}$ ( $20 \mathrm{nA}$ beam current) to strike a balance between reduced excitation volume and sufficient excitation of the Ti K $\alpha$ line. Where inclusion size allowed, measurements were also made with a $1 \mu \mathrm{m}$ beam diameter. The element map in figure $5 \mathrm{a}$ was carried out at $6 \mathrm{kV}$ accelerating voltage using a focused beam, a $500 \mathrm{~nm}$ step size and a dwell time of $500 \mathrm{~ms}$ per pixel.

Low accelerating voltage microprobe measurements are affected by additional issues resulting in reduced precision. Surface effects have a stronger influence on the low-energy L lines, thus a liquid nitrogen cold trap was used to reduce effects of hydrocarbon contamination. Improved matrix correction procedures were 
also employed. Excitation depths of $\mathrm{K}$ and $\mathrm{L}$ lines were modeled using Monte Carlo simulation to ensure all signals were coming from approximately the same excitation volume.

Energy dispersive X-ray Spectroscopy (EDX) and EBSD analysis

Full crystallographic orientations of the garnet lattice were determined by EBSD. Secondary electron and backscattered electron (BSE) images as well as EDX and EBSD analyses were collected on an FEI Quanta 3D FEG scanning electron microscope (SEM) at the Laboratory for Scanning Electron Microscopy and Focused Ion Beam Applications of the Faculty of Geosciences, Geography and Astronomy at the University of Vienna (Austria). The microscope is equipped with an EDAX Pegasus Apex 4 system consisting of an Apollo XV Silicon Drift Detector for EDX analysis and an EDAX Digiview IV EBSD camera at an elevation angle of $5^{\circ}$. EDX data were collected using the TEAM 3.1 software at beam conditions of $15 \mathrm{kV}$ and a spot size of $4.5(0.1$ $\mathrm{nA}$ ) in standard mode or spot size $1.0(4 \mathrm{nA})$ in analytic mode. For EBSD analyses the OIM DC v6.2.1 software was used. Beam conditions for all EBSD data were $15 \mathrm{kV}$ accelerating voltage and $2.5-4.0 \mathrm{nA}$ beam current with a $1 \mathrm{~mm}$ SEM aperture and an incidence angle of $20^{\circ}$ to the sample surface. The working distance was 10 $\mathrm{mm}$ for the map in figure $7 \mathrm{a}$ and $14 \mathrm{~mm}$ for all other data used in this paper. For mapping, EBSD camera binning was $4 \times 4$, with Hough settings of $1^{\circ}$ theta step size, a 9x9 convolution mask and a binned pattern size of 160 pixels (fig. 7a) or 140 pixels (fig. 8a), indexing 6 - 12 Hough peaks at a minimum peak distance of 12 and 10 pixels respectively. EBSD maps were collected at step sizes of $0.35 \mu \mathrm{m}$ (fig. 7a) and $0.4 \mu \mathrm{m}$ (fig. 8a) using a hexagonal grid.

Line profiles were acquired for evaluation by the pattern correlation-based HR-EBSD method, which compares small shifts in high resolution Kikuchi patterns directly to a chosen reference pattern to obtain precise rotations (Wilkinson et al. 2006). For line 29 (fig. 7) EBSD camera binning was 2x2 and each Kikuchi pattern was the average of 16 frames. For all other lines in this paper, binning was $1 \times 1$ and patterns were the average of 10 frames. Saved patterns for $1 \times 1$ binning were $863 \times 863$ pixels in size. Single point data were collected at step sizes of $1-1.5 \mu \mathrm{m}$ along $80-140 \mu \mathrm{m}$ long profiles.

Evaluation of EBSD patterns used the commercially available Cross Court 3 software produced by BLG Productions Limited (www.blgvantage.com). Initial data are in the form of rotation components around three orthogonal sample axes. These have been combined into single rotations using the Matlab ${ }^{\mathrm{TM}}$ toolbox MTEX (Bachmann et al. 2010; Hielscher et al. 2010), also used to calculate misorientations and plot pole figures (figs. 7d \& 8c). 
Transmission electron microscope (TEM) analysis

Targeted TEM foils were prepared by focused ion beam (FIB) using the previously introduced FEI Quanta 3D FEG instrument (University of Vienna). The dual beam instrument has a field emission liquid metal Ga source, gas injection systems for Pt- and C deposition and an Omniprobe ${ }^{\mathrm{TM}} 100.7$ micromanipulator for in-situ lift out of the TEM foils. Ion beam currents of $65-3 \mathrm{nA}$ were used for rough cuts during extraction of foils from the thin section, whereas progressively smaller beam currents from $1 \mathrm{nA}-30 \mathrm{pA}$ were applied for final thinning steps after transfer of the foil to a $\mathrm{Cu}$ grid. Fully thinned areas of foils had dimensions of approx. $6-10 \times 10-12$ x $0.1-0.3$ micrometers. The accelerating voltage was at $30 \mathrm{kV}$ throughout sputtering and gas deposition. Pt deposition was used for mechanical stabilization and mounting of the foils onto the $\mathrm{Cu}$ grid.

The TEM foils were examined using a Tecnai F20 X-Twin TEM at the GFZ Potsdam, operating at 200 $\mathrm{kV}$ with a FEG electron source. The TEM is equipped with a post-column Gatan imaging filter (GIF Tridiem). Phase identification was performed with an EDAX energy dispersive X-ray analyzer equipped with an ultrathin window, and also by indexing of diffraction patterns from energy filtered high resolution TEM images (a $10 \mathrm{eV}$ window was applied to the $0 \mathrm{eV}$ loss peak). The Gatan Digital Micrograph software was used to analyze the transmission electron micrographs. All images presented here are from scanning transmission (STEM) mode using a Fishione high angle annular darkfield (HAADF) detector, with camera lengths of $220-330 \mathrm{~mm}$.

Image analysis

BSE images taken using the previously introduced FEI Quanta 3D FEG SEM (University of Vienna) were thresholded using the image analysis software imageJ (Abràmoff et al. 2004) in order to calculate the approximate area taken up by inclusions. Approximate radii of selected phosphate inclusions were obtained via imageJ by manually drawing ellipses around inclusions. BSE images spanning a range of scales were used. The area of these ellipses was recorded and the radius of a circle of equivalent area calculated.

\section{Microstructural observations}

\section{Metapegmatite microstructures}

Sample 04T26K has a mylonitic foliation, although elements of the magmatic pegmatite microstructure are still apparent as porphyroclasts. The Permian pegmatite assemblage consisted of euhedral almandine-spessartine garnets with grain sizes of around $1 \mathrm{~cm}$, in equilibrium with coarse grained andalusite, perthitic K-feldspars, 
plagioclase (oligoclase), quartz, and tourmaline. The original grain size of andalusite crystals in $04 \mathrm{~T} 26 \mathrm{~K}$ is uncertain because the polycrystalline kyanite aggregates which formed from them are smeared out into augen. Accessory zircon (grain size $10-100 \mu \mathrm{m}$ ) occurs in the matrix. In thin section garnets show a dark, submicron inclusion rich core (see table 1 for a list of phases) and a clear, submicron inclusion poor rim (fig. 1a). The garnet rim contains anhedral quartz intergrowths with grain sizes up to $\sim 500 \mu \mathrm{m}$, and rare small zircons. Both rim and core domains in garnet are Permian age magmatic growth features (Thöni et al. 2008). Feldspars contain blade-shaped apatite inclusions $(<<1 \mu \mathrm{m} \times 1 \mu \mathrm{m} \times 10-200 \mu \mathrm{m})$.

The Cretaceous tectono-metamorphic event led to dynamic recrystallization of the pegmatite matrix and the formation of compositional layering and a mylonitic foliation. The foliation is defined by polycrystalline quartz ribbons, recrystallized feldspar and acicular kyanite; it is asymmetrically deflected around larger clasts.

Quartz grains range in size from $40-200 \mu \mathrm{m}$ in polymineralic matrix domains, but inside ribbons they range from $200 \mu \mathrm{m}$ to $\sim 1 \mathrm{~mm}$ in size, and are commonly elongated parallel to the stretching lineation. Large quartz grains often have lobate grain boundaries, indicating predominant grain boundary migration recrystallization. In larger grains patchy extinction indicates subordinate subgrain rotation recrystallization. Feldspar porphyroclasts exhibit elongate, rounded shapes and undulose extinction. The largest grains are crosscut by 200 - $500 \mu \mathrm{m}$ wide bands of subgrains and new grains (grain size ca. $50 \mu \mathrm{m}$ ). Smaller clasts often exhibit a core-mantle microstructure. Subgrains in all clasts have similar grain sizes to completely recrystallized grains $(40-150 \mu \mathrm{m})$, implying that the dominant deformation mechanism in feldspars was subgrain rotation recrystallization. Some plagioclase crystals show pinstripe deformation twinning. Polycrystalline aggregates of kyanite with individual grain sizes ranging from $25-150 \mu \mathrm{m}$ represent pseudomorphs after andalusite. These aggregates are associated with bands of fine grained kyanite needles $(\sim 5 \mu \mathrm{m} \times 10-100 \mu \mathrm{m})$.

The metamorphic assemblage comprises quartz + plagioclase (albite) + K-feldspar + muscovite + kyanite \pm tourmaline \pm garnet + accessory phases (apatite + xenotime + rutile, mostly in recrystallization zones in garnet). All andalusite was replaced by kyanite \pm muscovite. Garnet does not form new metamorphic nuclei, but rare, 10 - $50 \mu \mathrm{m}$ sized Ca-rich overgrowths on magmatic garnet may occur in contact with plagioclase (Habler et al. 2007, Bestmann et al., 2008).

Metapegmatite garnet microstructures

Micro- and nano-inclusion abundance zoning 
In hand specimen garnets exhibit dark red cores and pinkish rims. The darker core color is due to the presence of abundant inclusions, which range from $\sim 1 \mu \mathrm{m}$ to a few nanometers (see the section 'TEM data') in diameter. Thin sections show inclusions distributed in a series of concentric and sector zones in the garnet cores (fig. 1). This zoning is defined by spatial variation in inclusion abundance (the 'inclusion density'), size, and phase assemblage.

FEG-SEM and EDX analysis have identified seven fine grained inclusion phases: rutile, ilmenite, xenotime, zircon, corundum, apatite and an Fe-Mn phosphate classified as belonging to the wyllieite group (Moore and lto 1979). Habits and idealized formulae for each of the phases are listed in table 1. Analysis of BSE images shows that inclusions occupy $1-2 \%$ of the thin section surface area in inclusion-rich zones. Wyllieite group phosphate, ilmenite, rutile and corundum are most abundant. Xenotime and zircon are less common, and apatite inclusions are very rare. In the following sections, the micron- to sub-micron-sized inclusions that define zones in the garnet and are not located within any other microstructure are named 'out-trail' inclusions (fig. 2).

\section{Inclusion trails}

Trails of inclusions have been observed crosscutting the inclusion density zoning (fig. 1). Inclusions within trails are coarser than elsewhere in the garnet (commonly 1 - $3 \mu \mathrm{m}$ in diameter, rarely up to $10 \mu \mathrm{m}$ ). Trails consist of an array of separate inclusions defining a curviplanar surface in the garnet, hundreds to thousands of $\mu \mathrm{m}$ long and generally terminating inside the host garnet at one or both ends in the plane of the thin section. The garnet lattice between the inclusions comprising trails is continuous (figs. $3 \& 4$ ). The ends of some trails are observed to overlap with the start of a second trail in an en echelon configuration (fig. 3a). In this paper the coarser inclusions defining the approximately planar surfaces in the garnet are referred to as 'in-trail inclusions' (fig. 2).

Each trail exhibits a 'bleaching zone' flanking these coarser inclusions, within which sub-micron inclusions are less abundant or absent in optical microscope and SEM images (figs. 3 \& 4). Bleaching zone widths can be defined with a precision of about $\pm 10 \mu \mathrm{m}$ using this criterion. Bleaching zones are usually $10-$ $50 \mu \mathrm{m}$ wide, with rare examples up to $100 \mu \mathrm{m}$. Widths can vary along one trail. No strong correlation is seen between the grain size of in-trail inclusions and the bleaching zone width or intensity. However, bleaching zones are always wider than the diameter of the in-trail inclusions. In some cases bleaching zones appear free of inclusions in optical microscope and SEM images (figs. 3a $+b$ ), whereas in others only fine grained inclusions are absent while inclusions of similar diameter to the coarsest out-trail inclusions are present $(\max \sim 1 \mu \mathrm{m}$ 
diameter) (top left of fig. 3c). Along single trails the style of bleaching zone can change (fig. 3c). Inclusions not directly 'in-trail' but still within an obvious bleaching zone are referred to in this paper as 'in-BZ' inclusions (fig. 2). Bleaching zones have not been seen to affect in-trail or in-BZ inclusions of other trails. The designations 'inclusion trail' and 'trail' are used to refer to the complete microstructure comprising the association of coarser inclusions with a bleaching zone (fig. 2). The planar features defined by in-trail inclusions are referred to as the 'trail plane' and the intersection of the trail plane with the thin section surface as the 'trail trace' (fig. 2).

Trail abundance varies between garnets, but they are considerably more common in inclusion rich cores. Very rarely inclusion trails do extend a short distance into the clear rim. Subparallel, mica-filled cracks crosscut all other garnet microstructures.

A more detailed view of the trail microstructure was provided by higher resolution observations in the FEG-SEM aided by EDX (e.g. fig. 4). Two domains were subjected to a wide range of analytical techniques, KII and KVK. Both domains belong to garnets from the same sample, but separate thin sections. Each is $1-2$ $\mathrm{mm}^{2}$ in area and contains several intersecting inclusion trails.

All seven inclusion phases detailed in table 1 are also found within inclusion trails. EDX does not resolve any compositional difference between these inclusions and corresponding out-trail phases, with the exception of in-trail and in-BZ wyllieite group inclusions from domain KVK (see the section 'quantitative compositional data'). Inclusion trails from domain KII do not contain additional phases; in contrast, rare muscovite, $\mathrm{Zn}$-Sn spinel, Fe-Mn carbonate and chlorite inclusions have been identified as in-trail inclusions in domain KVK, though not all of these occur in each trail. Trails in domain KVK also contain a greater relative abundance of apatite than observed out-trail in this garnet, although wyllieite group phosphate, ilmenite and corundum remain most abundant.

Trails in domain KVK exhibit pores at the thin section surface (figs. $4 b+c$ ). Pores are only found directly in-trail, and are less common than any of the seven major solid inclusion phases. In contrast, only one pore was found in domain KII. Pore abundance is variable along trails in domain KVK. Greater pore abundance is weakly correlated with a greater dominance of apatite in trails and greater abundance of phases not belonging to the out-trail assemblage. Attempts to find closed pores below the garnet surface yielded negative results. Raman spectroscopy was used on several candidate inclusions, but only solid phases were detected. However, 
inclusion diameters of ca. $1 \mu \mathrm{m}$ are at the lower limit from which a signal can be obtained by confocal Raman spectroscopy, so non-detection cannot definitively rule out the presence of fluid phases.

\section{Deformation zones}

Deformation zones and associated bleaching zones consistent with the observations of Bestmann et al. (2008) can be identified in all thin sections. Microstructural evidence of dynamic garnet recrystallization is common in rim domains, but intragranular shear zones cutting both core and rim are rare and unevenly distributed. Such deformation zones do not represent the main focus of the current study and were not analyzed further.

\section{Quantitative compositional data}

It is necessary to determine whether the inclusion trail microstructure formed isochemically or required material exchange with the garnet. Quantitative analyses of inclusion and garnet compositions were carried out in domains KII and KVK. An excitation volume diameter of $<1 \mu \mathrm{m}$ was obtained using a field emission gun electron microprobe at low accelerating voltages (see methods section). To calculate compositions in terms of atoms per formula unit (apfu), data were normalized to a fixed number of oxygen atoms per formula unit, noted in the relevant table for each phase (tables $2 \& 3$ and Online Resources $1 \& 2$ ).

Garnet composition

Garnet compositions obtained at accelerating voltages of 15 and $20 \mathrm{kV}$ were used as internal standards for the calibration of $6 \mathrm{kV}$ measurements. Measurements for calibration were made in optically inclusion-free garnet close to one trail for domain KVK, and in the nearby inclusion-free rim for domain KII. Table 2 lists the mean composition of garnet in domains KVK and KII and in the KII rim. For domain KVK it is possible to compare $20 \mathrm{kV}$ and $6 \mathrm{kV}$ analyses. The $6 \mathrm{kV}$ data reported is the mean of 230 measurements from a line profile that was not specifically targeted to avoid inclusions. The $6 \mathrm{kV}$ measurements are in reasonable agreement with the 20 $\mathrm{kV}$ values; the higher concentrations of minor elements detected at $6 \mathrm{kV}$ are due to a greater relative contribution from inclusions, not due to calibration errors.

TEM observations (see the section 'TEM data' and figure 9) revealed that all measurements unavoidably contain a contribution from ubiquitous inclusions 2 - $50 \mathrm{~nm}$ in diameter. However, nanoinclusions comprise a very small percentage of the excitation volume and are unlikely to affect major element totals significantly. 
The metapegmatite garnet core domains are almandine-spessartine rich with very small pyrope and grossular components ( $\sim 1.5$ and $\sim 0.5$ mol\% respectively). Optically inclusion-free garnet has a minor P component (0.02 apfu), but other minor elements are present only at very low concentrations (Ti $0.002 \mathrm{apfu}, \mathrm{Na}$ $0.007 \mathrm{apfu}$ ) and likely represent contamination from nanoinclusions. No Y at all was detected.

Qualitative element mapping (domain KII, fig. 5a) does not resolve any compositional change in garnet across bleaching zones. Likewise, no systematic trends in composition correlating with the bleaching zone location were noted in a line profile of quantitative $6 \mathrm{kV}$ microprobe analyses (domain KVK, fig. 5b) for any of the 10 elements analyzed.

Inclusion compositions

Inclusion compositions were analyzed both inside and outside trails for wyllieite group phosphate in domains KII and KVK and for rutile in domain KII. In-trail and in-BZ ilmenite and rutile inclusions in domain KVK were also analyzed, but out-trail inclusions of these phases were too small. Apatite inclusions were not stable under the electron beam. Zircon and xenotime inclusions were too rare to deliver good sampling statistics. Tabular corundum inclusions proved too thin for analysis.

\section{Wyllieite group phosphates}

Weight percent totals for wyllieite group phosphates are generally between 102 and $105 \mathrm{wt} \%$. Some beam damage was observed after analysis of wyllieite inclusions, which could explain the excess totals. Totals are up to $2 \mathrm{wt} \%$ higher for $6 \mathrm{kV}$ measurements in domain KII relative to domain $\mathrm{KVK}$ using the same calibration, likely due to differences in coating thickness or polished surface quality.

The precision of these data was checked by repeated analyses of five different inclusions under identical conditions; systematic changes between measurement sessions and between a focused beam and $1 \mu \mathrm{m}$ spot size were also examined. Maximum compositional variations were found to be around \pm 0.1 apfu, consistent with expectations for $6 \mathrm{kV}$ microprobe measurements.

The mean compositions of out-trail wyllieite group phosphates from domains KVK and KII are listed in table 3. A compositional trend was not observed for out-trail inclusions in either domain. Only two out-trail phosphates in domain KII could be analyzed without garnet contamination of the activation volume. As the composition of in-trail and in-BZ phosphates does not differ from out-trail phosphates in domain KII (fig. 6b), including these 
in the mean provides a more robust assessment of the wyllieite group phosphate composition there (table 3). Applying the site assignment method of Moore and lto (1979) results in classification of the analyzed inclusions as qingheiite (Ma et al. 1983) with qingheiite-(Fe2+) (Hatert et al. 2010) (the assigned Fe occupancy of the $\mathrm{M}(1)$ site places them at the compositional boundary).

Despite the similarity in the composition of their out-trail inclusions, domains KII and KVK differ considerably in the composition of their in-trail and in-BZ inclusions (fig. 6). Wyllieite group phosphate inclusions in trails from domain $\mathrm{KVK}$ show strong variations in their $\mathrm{Ca}, \mathrm{Mg}, \mathrm{Mn}$ and $\mathrm{Fe}$ contents. Figure $6 \mathrm{a}$ plots atoms per formula unit of $(\mathrm{Mn}+\mathrm{Ca})$ against $(\mathrm{Fe}+\mathrm{Mg})$ for domain $\mathrm{KVK}$. The data follow a trend of increasing $(\mathrm{Mn}+\mathrm{Ca})$ with decreasing $(\mathrm{Fe}+\mathrm{Mg})$; a line of best fit through all the data points gives a slope of 1.1 , with an $\mathrm{R}^{2}$ value of 0.94 .

Wyllieite group phosphate inclusions in trails from domain KII do not exhibit any of the variation in composition seen in domain KVK. Phosphates have a constant composition in all trails examined, and this composition is identical to that of the out-trail inclusions within the precision of measurement. Atoms per formula unit of $(\mathrm{Mn}+\mathrm{Ca})$ vs. $(\mathrm{Fe}+\mathrm{Mg})$ for all analyzed inclusions in domain $\mathrm{KII}$ are plotted in figure $6 \mathrm{~b}$. The two groups of points overlap well, though there is a scattering of compositions along a line of constant $(\mathrm{Mn}+\mathrm{Ca}) /(\mathrm{Fe}+\mathrm{Mg})$ ratio (marked). This trend is an artifact caused by poorer quantitative results for some inclusions. Data points with totals $>106 \mathrm{wt} \%$ and $/$ or $\mathrm{SiO}_{2}$ contents $>1 \mathrm{wt} \%$ are indicated and represent all of the points with the most scatter.

\section{Ti phases}

In order to achieve full excitation of the Ti K $\alpha$ line, all Ti phases were analyzed at an accelerating voltage of 10 $\mathrm{kV}$, resulting in improved precision compared to $6 \mathrm{kV}$ measurements.

Mean rutile compositions organized by domain and trail are listed in Online Resource 1. Inclusions show elevated $\mathrm{Fe}^{3+}, \mathrm{Nb}$ and $\mathrm{Ta}$ concentrations. Calculated $\mathrm{Fe}^{3+}$ contents comprise $100 \%$ of available $\mathrm{Fe}$ as $\mathrm{Fe}^{3+}$. Minor trace elements are Sn, Mn, and Si. Four analyses were made of out-trail rutile inclusions, all in domain KII. None showed any differences from the composition of in-trail and in-BZ rutiles. Rutile compositions in different trails in domain KII were identical within error. 
Analyzed in-trail rutiles in domain KVK contain more $\mathrm{Nb}$, Ta and $\mathrm{Fe}^{3+}$ than those of domain KII. There is resolvable variation in $\mathrm{Nb}, \mathrm{Ta}, \mathrm{Fe}^{3+}$ and $\mathrm{Ti}$ concentrations between rutiles belonging to different trails in domain KVK (not included in Online Resource 1), reaching up to ten times the variation in a single trail.

Ilmenite is rare in domain KII, so only inclusions in domain KVK were analyzed. Out-trail inclusions were not large enough for analysis. Mean ilmenite compositions organized by trail are listed in Online Resource 2. Ilmenites contain around 0.2 apfu $\mathrm{Mn}$, and 0.1 apfu $\mathrm{Fe}^{3+}$ calculated by charge balance. Only minor amounts of $\mathrm{Si}, \mathrm{Al}, \mathrm{Nb}$ and $\mathrm{Ta}$ are present. Ilmenite from different trails in domain KVK possesses resolvably different $\mathrm{Mn}$ and $\mathrm{Fe}$ concentrations.

\section{EBSD data}

Crystallographic orientation mapping

EBSD mapping shows that inclusion trails are associated with garnet lattice rotation. Six inclusion trails were mapped, and all showed the features summarized in this section. Representative EBSD maps are shown in figures 7a and 8a. Maps reveal bands of garnet with very small but systematic misorientation relative to the uniform orientation of the surrounding crystal. These bands spatially correlate with the visible extent of bleaching zones (figs. 7a + b, figs. $3 c$ \& 8a). As the true misorientation differences in bleaching zones are below the precision of 2D Hough transform-based EBSD, absolute values are incorrect. The map indicates only the general distribution of misoriented garnet.

High angular resolution EBSD analysis by the cross correlation-based method

The cross correlation-based method was employed to resolve the true misorientation in and across bleaching zones (see methods section). Parallel lines of EBSD point analyses were collected across each of the inclusion trails mapped. Misorientation angles and axes were calculated relative to a reference point, chosen as the point in each profile with the maximum misorientation angle to the first point (marked with a dashed vertical line in figures $7 c$ and $8 b)$.

\section{Misorientation angle profiles}

Profiles of misorientation angle against distance (figs. 7c \& 8b) show similar shapes. Note that misorientation angle to the central reference point is plotted positive downward. The widths of the bands of misoriented garnet correlate well with the widths of corresponding bleaching zones. Garnet outside bleaching zones shows little 
orientation change. Misorientation angle to garnet outside trails gradually increases towards the center of bleaching zones. The maximum misorientation angle to garnet outside bleaching zones is found approximately at the trail plane/trace, and the misorientation angle gradient is shallower for $10-20 \mu \mathrm{m}$ either side of this point. Maximum misorientation angles from the reference point to the trail edge range from $0.1-0.45^{\circ}$. The two blocks of garnet on opposing sides of the bleaching zone commonly display a small systematic misorientation to each other of up to $0.1^{\circ}$ (e.g. fig. $7 \mathrm{ci}+\mathrm{ii}$ ).

Profiles in domain KII are symmetrical, whereas in domain KVK profiles are slightly asymmetrical. For most profiles gradients in misorientation angle are on the order of $0.01^{\circ}$ per $\mu \mathrm{m}$, sustained over $10 \mathrm{~s}$ of $\mu \mathrm{m}$. Rarely a more abrupt step in the profile is seen (e.g. figs. 7cii \& 8biii), with point to point misorientation angles reaching $0.1^{\circ}$. The abruptness of the orientation change is variable along the strike of the trail edges.

\section{Misorientation axes}

The cross correlation-based method allows the determination of misorientation axes with greatly improved precision with respect to the standard 2D Hough transform-based EBSD method. Misorientation axes of rotated garnet correlated with bleaching zones were plotted for all points where misorientation angle exceeded $0.05^{\circ}$ from the reference (figs. $7 \mathrm{~d} \& 8 \mathrm{c}$ ). Using the formula of Bate et al. (2005) and a conservative angular precision of $\pm 0.04^{\circ}$ (inferred from orientation recorded outside trails), the precision of axis determination is calculated to be $\pm 39^{\circ}$ for a $0.05^{\circ}$ misorientation angle, improving to $\pm 5^{\circ}$ for an angle of $0.45^{\circ}$. These values agree well with the observed dispersion of misorientation axes.

In general, misorientation axes with respect to the central reference point are different on either side of the trail trace (figs. $7 \mathrm{~d}$, fig. 8 ciii + iv). There are two exceptions, found in adjacent profiles across the same trail (fig. $8 \mathrm{ci}+$ ii). The angle between the two groups of misorientation axes ranges from $\sim 0^{\circ}$ to $\sim 50^{\circ}$ depending on the trail, but along each trail the orientation of the two groups of axes remains relatively constant.

All the examined trail planes are roughly perpendicular to the thin section surface, allowing comparison of how misorientation axes are orientated with respect to the trail plane. In domain KVK, misorientation axes tend to be inclined at $45-60^{\circ}$ to the thin section surface normal, and the strikes of the axes are at $60-90^{\circ}$ to the trail trace, (fig. $7 \mathrm{~d}$ ). In domain KII, misorientation axes are inclined at $30-60^{\circ}$ to the thin section surface normal and are much closer to lying within the plane of trails (fig. 8c). In general misorientation axes do not coincide with low indexed crystallographic directions. 
As long as the chosen reference point is located within the region of shallower misorientation angle gradient in the center of trails ( $\pm 10-20 \mu \mathrm{m}$ from the reference point used here), varying it has little effect on calculated misorientation angles and axes. The only exception is profile 34 , where misorientation axes are highly variable even for adjacent reference points near the trail trace. The reference point for line 34 was therefore chosen at the far end of the profile and misorientation axes were not calculated separately for the two flanks (fig. 7div).

\section{TEM data}

TEM allows corroboration of EBSD data with direct observations of defects, and characterization of inclusions below the resolution of the FEG-SEM. Six thin foils were extracted from key locations (see methods section and figs. 7a \& 8a). Three settings were compared: The central part of the inclusion trail, the edge of the bleaching zone, and the inclusion rich garnet outside the bleaching zone.

Submicron inclusions

Foils display no noticeable difference in the distribution of the smallest inclusions, ranging from $\sim 2 \mathrm{~nm}$ to $\sim 50$ $\mathrm{nm}$ in diameter (fig. 9). Numbers of inclusions in this size range are estimated to be on the order of $10^{3}$ per $\mu \mathrm{m}^{3}$ and they appear randomly distributed. Phases conclusively identified (by HRTEM indexing) are ilmenite and monazite; EDX implies the presence of zircon, possible xenotime and/or apatite, possible rutile, a $\mathrm{Zn}-\mathrm{Sn}$ - $\mathrm{Al}$ oxide and a $\mathrm{Nb}-\mathrm{Ta}-\mathrm{Sn}$ oxide.

The abundance of inclusions $>\sim 50 \mathrm{~nm}$ in diameter differs between the different microstructural settings as expected. Outside the bleaching zone inclusions exceeding $50 \mathrm{~nm}$ in diameter are much more common (figs. $9 \mathrm{a}-\mathrm{d}$ ). The phase assemblage at diameter $>50 \mathrm{~nm}$ mostly reflects the phases detected in the SEM: ilmenite, Nb-Ta-Sn bearing rutile, xenotime, zircon, corundum, and wyllieite group phosphate are all present.

\section{Dislocations}

Outside the bleaching zone and in a foil cut across the center of a trail in domain KVK, only one or two dislocations are seen per foil. In foils sampling the margins of bleaching zones, STEM imaging reveals more dislocations (around 10-20 times as many), however dislocation density (roughly $10^{11} \mathrm{~m}^{-2}$ ) remains below that which can be counted via TEM with statistical reliability. Dislocations are not organized into a regular subgrain 
wall arrangement. Dislocation segments tend to be long and relatively straight; no tangling is seen between dislocations and they are not pinned at any inclusions (fig. 9e - h).

\section{Discussion}

The inclusion trail microstructure cuts the magmatic inclusion zoning and within bleaching zones the original inclusion size distribution is clearly altered. Inclusion trails therefore definitely represent a re-equilibration microstructure.

Origin of submicron inclusions in garnet

The 'out-trail' inclusions are older than the inclusion trail microstructure, as demonstrated by crosscutting relationships (figs. 1, 3 - 4). The observed inclusion density zoning patterns are typical of magmatic growth zoning, implying that the submicron inclusions originated during the Permian crystallization of the pegmatite. Specifying the origin mechanism of the inclusions is beyond the scope of the current paper. The process by which the magmatic inclusions came to be included in the garnet is unlikely to have affected the later reequilibration process.

Brittle precursors of inclusion trails

The distribution of 'in-trail' inclusions is interpreted to reflect the presence of now healed brittle cracks, based on their arrangement as if on curviplanar surfaces that crosscut the magmatic zoning (figs. $1 \& 3$ ). These features could not have arisen via overgrowth of existing fabrics. Most importantly, adjacent inclusion trails sometimes overlap in an en-echelon arrangement (fig. 3a), characteristic of brittle fracture (Mancktelow and Pennacchioni 2005).

These precursor cracks have fully healed. No defects could be located at the proposed crack trace in TEM foils, implying almost no misfit between the two sides of the crack and/or some recrystallization of the garnet after healing. There is no abrupt orientation change at the inferred crack plane (figs. $7 \& 8$ ), although either side of bleaching zones the two opposing blocks of garnet are often misoriented to each other by up to $0.1^{\circ}$ (fig. $7 \mathrm{ci}+\mathrm{ii}$ ). The very small rotation across the crack plane implies that fracturing was not accompanied by further deformation before healing (e.g. Trepmann and Stöckhert 2002; Vernooij et al. 2006).

Closed and open system behavior in trails 
Compositional data are employed to determine the extent of material exchange between different garnet domains and the rock matrix. This section assumes that microstructural and chemical re-equilibration of inclusions occurred during the eo-Alpine tectono-metamorphic event (this assumption is addressed at the end of the discussion).

\section{Host garnet}

Electron microprobe analyses cannot resolve any differences in garnet major element composition across bleaching zones (fig. 5), implying that garnet did not alter its composition by material exchange with the matrix or with re-equilibrating inclusions. This is unsurprising as metamorphic reactions involving garnet in the metapegmatite are restricted to immediate contacts with plagioclase, where only $10-50 \mu \mathrm{m}$ thick metamorphic garnet overgrowths formed. Fluid undersaturated conditions during the eo-Alpine tectono-metamorphic event (Tenczer et al. 2006) offer a plausible explanation for the low reaction rates in these rocks, corroborated by the continued presence of recrystallized K-feldspar even at inferred eclogite facies conditions.

The eo-Alpine event was short lived $(<10 \mathrm{Ma})$ and reached an absolute maximum temperature of 750 ${ }^{\circ} \mathrm{C}$ (Thöni 2006; Bestel et al. 2009). The modeling work and measurements of Gaidies et al. (2008) show that at these temperatures sufficiently small compositional variations could be smoothed out by diffusion within the timescale of the eo-alpine event (e.g. their fig. 10). However, local Ca-rich eo-Alpine garnet overgrowths are still detectable. This implies that if there ever was a garnet composition difference in bleaching zones that was erased by diffusion it must have been even smaller than that found locally at rims.

The data suggest that the composition of the host garnet was essentially unchanged throughout the reequilibration of inclusions. Garnet re-equilibration in these trails was either kinetically inhibited or the pegmatite garnet composition was stable under the conditions prevalent within trails throughout the period that the system was open.

\section{Inclusions}

Wyllieite group phosphates are a good proxy to detect deviations from isochemical behavior; they are able to incorporate a wide variety of elements common in garnet and the rock matrix. In-trail and in-BZ wyllieite group phosphate inclusions in domain KII have identical compositions to out-trail inclusions (fig. 6b). The same is found for the few rutile inclusions analyzed (Online Resource 1). Coarsening in domain KII is therefore interpreted to be isochemical. This is supported by several other observations: there is no variation in 
composition within the population of in-trail and in-BZ inclusions of either phase, all phases found within trails in domain KII also occur outside them, and garnet composition does not change across trails.

In contrast to domain KII, domain KVK shows non-isochemical behavior (fig. 6a). All in-trail and in$\mathrm{BZ}$ wyllieite group phosphate compositions in domain KVK scatter along a trend line originating from the mean out-trail composition, implying activity of the exchange $(\mathrm{Mn}, \mathrm{Ca})_{+1}(\mathrm{Fe}, \mathrm{Mg})_{-1}$. Additionally, trails in domain KVK occasionally contain phases with components likely to originate from the rock matrix, such as muscovite $(\mathrm{K})$, chlorite $\left(\mathrm{H}_{2} \mathrm{O}\right)$ and Fe-Mn carbonates $\left(\mathrm{CO}_{2}\right)$. Apatite is also more abundant within these trails than outside them. Only a single pore was found in domain KII, whereas pores are more common in-trail in domain KVK (figs. $4 \mathrm{~b}+\mathrm{c}$ ). It is a reasonable assumption that pores contained fluid, considering they often contain small crystals which can be interpreted as possible daughter crystals (fig. $4 b+c)$. The greater abundance of pores in domain KVK relative to domain KII supports the evidence from the inclusion assemblage that volatile involvement in trail formation was greater in the former domain.

\section{Isochemical behavior and differences between domains}

The key implication from comparison of the compositional behavior of domains KVK and KII is that formation of the inclusion trail microstructure did not require exchange with the rock matrix and coarsening occurred isochemically in some trails. The changes observed in domain $\mathrm{KVK}$ represent an additional process which was not the trigger for inclusion trail formation.

While the presence of new phases indicates that some material exchange between the garnet interior and the rock matrix occurred in domain $\mathrm{KVK}$, the inclusion assemblage did not reach a uniform equilibrium composition. Compositions of the three inclusion phases studied in detail vary within single trails (wyllieite group phosphates, fig. 6a) and between neighboring trails (Ti-bearing phases, e.g. Online Resource 2) in domain $\mathrm{KVK}$, over length scales of $10 \mathrm{~s}$ to $100 \mathrm{~s}$ of $\mu \mathrm{m}$. These data show that transport processes were not fast enough to homogenize inclusion trails during the time that parts of the system remained open.

Driving force of coarsening

The fact that at least some of the inclusion trails formed isochemically suggests that the coarsening was driven by capillary forces (Ostwald ripening). This involves chemical mass transfer by diffusion of material from smaller to larger particles without changes in the bulk composition of the host-particle assemblage. It is driven 
by the difference in mean curvature and surface area to volume ratio between differently sized particles of a phase (Balluffi et al. 2005). Coarser particles are more thermodynamically stable.

Inclusions $<\sim 50 \mathrm{~nm}$ in diameter are unexpectedly equally abundant inside and outside bleaching zones (fig. 9). The sub $50 \mathrm{~nm}$ phases are dominated by highly charged cations with low diffusivity in garnet. These observations imply that a separate, garnet-wide process accounts for their existence. If the tiny inclusions formed prior to coarsening, the low mobility (diffusivity * concentration) of their cations might have prevented coarsening in trails from efficiently consuming them. Alternatively, if some coarsening occurred throughout the garnet and it was merely more extreme in bleaching zones, the tiny inclusions could represent concentrations of low mobility elements stabilized as they are less efficiently transferred from small to large particles. A final possibility is that they formed by exsolution after coarsening finished.

Spatial distribution of coarsening / bleaching, and origin of lattice defects

Coarsening was limited to zones flanking healed cracks, or at least occurred considerably faster there. This implies the kinetics within the bleaching zone were different to those in the remaining garnet interior. $\mathrm{T}$ is assumed to have been homogenous over the host garnet. Heterogeneous coarsening rates must have been controlled by locally varying diffusion rates in garnet.

Bleaching zones are spatially correlated with increased dislocation density. The presence of geometrically necessary dislocations is inferred from lattice rotations and is confirmed by direct observation in TEM foils (fig. 9e - h). Geometrically necessary dislocation densities were estimated using STEM micrographs of whole TEM foils rather than lattice curvatures. Three foils with thinned areas of ca. 10 x $15 \mu \mathrm{m}$ were used. Dislocation densities inside bleaching zones are around 10x greater than outside them, although low in absolute terms (ca. $10^{11} \mathrm{~m}^{-2}$, counting statistics are not reliable with so few dislocations per foil, fig. $9 \mathrm{e}-\mathrm{h}$ ). The value of ca. $10^{11} \mathrm{~m}^{-2}$ is in agreement with the edge dislocation density required to generate the observed lattice rotation angle gradient of $0.01^{\circ}$ per $\mu \mathrm{m}$, using the formula of Tucker et al. (2000) and a garnet burgers vector of $1 \mathrm{~nm}$ (e.g. Voegelé et al 1998a). This formula returns the spacing of dislocations in a $0.01^{\circ}$ tilt boundary, which is inversely proportional to the dislocation density. Note that in the bleaching zone, dislocations are not organized into boundaries.

Increased dislocation density has been proposed to enhance transport rates due to higher rates of diffusion along dislocations (Ruoff and Balluffi 1963; Chakraborty and Ganguly 1991; Heidelbach et al. 2009), 
and is the favored hypothesis to explain the faster transport kinetics inside bleaching zones. For this to be correct, it must be proven that dislocations are a direct consequence of fracturing, the initial event in the development of an inclusion trail. If the dislocations were found to have no connection to fracture, it would imply that they became localized in the bleaching zone after it formed. In this case, the mechanism linking fracture and bleaching zone formation would not have involved dislocations; dislocations would be a result of bleaching zone formation, not part of its controlling mechanism.

The source of the diffusion-enhancing dislocations is interpreted to be as follows: at crack tips, stress concentrations exceeded the yield stress of the garnet, leading to local crystal-plastic deformation (Anderson 2005). Dislocations were generated near (and/or emitted from) the crack tip (e.g. Rice and Thomson 1974; Ohr 1985). Dislocations associated with crack tips have previously been observed in experimentally deformed garnets (Voegelé et al. 1998a, their fig. 10). Depending on the ductility of a material at the conditions of fracturing, zones of crystal plastic deformation can be much wider than the crack itself and a plastic 'zone' or 'wake' of dislocations can remain behind the propagating crack tip (e.g. Uğuz and Martin 1996; Gourgues 2002; Anderson 2005). The current EBSD data are interpreted to show a plastic wake in the garnet host crystal.

EBSD and cross correlation-based methods have been used to detect and measure the width of plastic zones in metals (Tucker et al. 2000; Wilkinson et al. 2006). In the cited examples, zones were up to $50 \mu \mathrm{m}$ wide in a nickel-based superalloy, but these values are not directly comparable with the current results. The dislocation densities inferred by Tucker et al. and Wilkinson et al. are 3 orders of magnitude greater, indicative of the far greater plasticity of their samples. In addition, the dominant burgers vector in nickel is 4 times smaller than in garnet. At comparable dislocation densities to those in this study, misorientation angles would be 4 times smaller for nickel (Tucker et al. 2000, equation 1). Therefore, dislocation densities similar to those documented here are hard to resolve in nickel even by cross correlation-based EBSD. If Wilkinson et al. had been able to map the extent of the plastic zone out to dislocation densities approaching $10^{11} \mathrm{~m}^{-2}$ it is likely that their measured plastic zone widths would have been much greater.

The misorientation axis data uniquely link the observed dislocations to fracture. The garnet lattice in the central region of most inclusion trails is misoriented around different axes with respect to the lattice on either side of the trail. Non-parallel misorientation axes indicate that two different slip systems (or combinations of slip systems) were activated either side of the trail plane (Prior et al. 2002). So-called 'asymmetric' plastic wakes occur at fractures in single crystals with no special orientation relationship to the crystal (Crone et al. 
2004, Pippan et al. 2004). The stress vectors either side of a crack plane will always act in different directions (Anderson 2005). When a crack plane has only a general orientation in a single crystal, the different stress vectors either side of the crack can activate different slip systems. The activity of two different slip systems (or combinations of slip systems) either side of the trail plane in this microstructure strongly suggests that the observed dislocations belong to the asymmetric plastic wake of a now-healed crack. The combinations of slip systems activated either side of a crack may share a misorientation axis if a crack plane lies close to a special orientation, as seen at one trail in domain KII (fig. $8 \mathrm{ci}+$ ii).

Axes in domain KVK lie closer to the trail plane normal, implying a larger screw dislocation component (fig. 7d). Axes in domain KII lie closer to and sometimes within the trail plane, implying a larger edge dislocation component (fig. 8c). None of the clusters of misorientation axes lies directly on top of a low indexed garnet axis, confirming activity of multiple slip systems.

Bleaching zones have a relatively uniform width over short distances, giving the appearance of enhanced volume diffusion rather than pipe diffusion. This requires diffusing species to have visited a number of dislocations during the timescale of coarsening, which is less likely if dislocations are separated by large distances (Ruoff and Balluffi 1963). This problem is overcome if dislocations were mobile during coarsening.

Volatiles could have played a role in enhancing diffusion within the areas of higher dislocation density and allowing enhanced volume rather than only pipe diffusion. However, the location and width of bleaching zones was not controlled by volatiles. Bleaching zones in domain KII are wider than those in domain KVK, despite the greater volatile input and material exchange with the rock matrix inferred for the latter. If the spatial distribution of coarsening was controlled by diffusion of volatiles into the garnet, the restriction of dislocations to bleaching zones needs to be explained separately. To generate dislocations only inside these zones, garnet in trails would have to have been easier to deform than garnet outside of trails. If the entire bleaching zone deformed crystal plastically in this way the same slip systems would be activated in both flanks of the bleaching zone, resulting in parallel misorientation axes. Dislocations would also be expected to pile up at the boundaries of bleaching zones where mechanical properties changed. Neither of these features is observed.

Estimate of the degree of diffusion enhancement

In a system which has undergone diffusion-controlled coarsening due to capillary forces, an equation links the evolution of mean particle size to a diffusion coefficient (Balluffi et al. 2005, eq. 15.18). Assuming isochemical 
coarsening (as in domain KII), the diffusion coefficient is the only variable which is different inside the bleaching zone and an expression for the ratio of the two diffusion coefficients, $D_{\text {trail }} / D_{\text {out }}$, can be written. $<R_{\text {trail }}>,\left\langle R_{\text {out }}>\right.$ and $\left\langle R_{0}>\right.$ are the mean particle radii within the trail, outside the trail, and before the onset of coarsening respectively.

$$
\frac{<R_{\text {trail }}>^{3}-<R_{0}>^{3}}{<R_{\text {out }}>^{3}-<R_{0}>^{3}}=\frac{D_{\text {trail }}}{D_{\text {out }}}
$$

Particle radii were measured by image analysis in domain KII for wyllieite group phosphates, as they best approximate the spherical geometry assumed by the equation. Histograms (Online Resource 3 ) were plotted in order to obtain approximate values for $\left\langle R_{\text {trail }}>(750 \mathrm{~nm})\right.$ and $\left\langle R_{\text {out }}>(125 \mathrm{~nm})\right.$ for this domain. Because $<R_{0}>$ is not constrained, only a minimum value of $D_{\text {trail }} / D_{\text {out }}$ can be calculated, for the case that $\left\langle R_{0}>\right.$ is much less than $<R_{\text {out }}>$. Substituting in the measured radii reveals that diffusion within bleaching zones in domain KII has been enhanced by a minimum factor of $10^{2}$. In practice this factor was probably higher, as $<R_{0}>$ is expected to be closer to $<R_{\text {out }}>$. If $<R_{0}>\approx 0.9 *<R_{\text {out }}>$ is used, the factor rises to $10^{3}$.

Relative timing of events during microstructure development

Conclusions about the fundamental mechanism linking fracturing to re-equilibration are not affected by the choice of chronological scenario. The idea that defects introduced by fracturing enhance transport and allow for localized coarsening is independent of the absolute timescale over which these events occurred.

Three scenarios are compatible with available evidence from crosscutting relationships: a) fracturing and coarsening both occurred during the eo-Alpine event, $\mathrm{b}$ ) fracturing and coarsening both occurred during the Permian event, or c) fracturing occurred in the Permian and coarsening in the eo-Alpine event. Scenario a) is favored based on the available data. It is considered unlikely that coarsening and bleaching zone formation occurred during the Permian due to the fact that these are also seen associated with eo-Alpine recrystallization zones in these garnets. If coarsening of inclusions occurred during both events, then two separate but similar processes would need to be invoked to account for this. Furthermore, two stages of coarsening are not observed in trails. Scenario c) is considered unlikely as well, because the Permian event is not associated with significant deformation. For example, cm-sized andalusite crystals were able to crystallize undisturbed in the metapelitic country rocks at this time.

\section{Conclusions}


The combination of spatially correlated data from a wide range of high resolution techniques leads to the following conclusions concerning the formation of the inclusion trail microstructure:

1. Inclusion trails with bleaching zones are located at the site of healed brittle cracks.

2. The inclusion trail microstructure is a product of re-equilibration that can occur isochemically, though some inclusion trails indicate increased material transport and fluid access. Nonetheless, complete compositional re-equilibration of coarsened inclusions with the rock matrix is never observed.

3. The mechanism of isochemical coarsening of inclusions is inferred to be Ostwald ripening, this was limited to (or occurred faster in) the vicinity of healed cracks.

4. Diffusion rates through the host garnet were enhanced adjacent to healed cracks.

5. Enhanced diffusion in bleaching zones is inferred to be due to higher dislocation density in this area. Diffusion coefficients are enhanced by a minimum factor of $10^{2}$ by an increase in dislocation density of one order of magnitude in domain KII.

6. Increased dislocation density (and hence enhanced diffusion) is directly linked to fracture. Dislocations are inferred to have been emitted from the crack tip during fracture and represent a plastic wake.

7. Misorientation axes of rotated garnet (misorientation angles $\leq 0.5^{\circ}$ ) are different either side of healed crack traces, indicating the activity of different slip systems in the two halves of the bleaching zone. This is best explained as an example of asymmetric crack wake plasticity (e.g. Pippan et al. 2004).

In summary, fracture can affect the intact crystal lattice adjacent to crack planes by the introduction of dislocations, priming these areas to respond differently to changing conditions due to enhanced diffusion rates. Healed cracks represent sources of heterogeneity which can affect the subsequent behavior of inclusion-rich host crystals during metamorphism and deformation. Re-equilibration of host-inclusion systems via this process can be local and isochemical, making it difficult to detect.

\section{Acknowledgements}

The authors acknowledge funding by the University of Vienna doctoral school IK052 Deformation of Geological Materials (DOGMA) and the project of the Austrian Science fund (FWF): I471-N19, as part of the international DFG-FWF funded research network FOR741-DACH. Dr. Stefan Zaefferer of the Max Planck Institute for Iron research is thanked for his provision of access to the Cross Court 3 software. T. L. Grove 
(editor), D. L. Whitney (reviewer) and an anonymous reviewer are thanked for their constructive and insightful comments which greatly improved the manuscript.

\section{References}

Abràmoff MD, Magalhães PJ, Ram SJ (2004) Image processing with imageJ. Biophotonics Int 11:36-41.

Anderson TL (2005) Fracture Mechanics: Fundamentals and Applications, Third Edition. CRC Press

Armstrong JT (1995) CITZAF: a package of correction programs for the quantitative electron microbeam Xray-analysis of thick polished materials, thin films, and particles. Microbeam Anal 4:177-200.

Bachmann F, Hielscher R, Schaeben H (2010) Texture analysis with MTEX- Free and open source software toolbox.

Balluffi RW, Allen S, Carter WC (2005) Kinetics of Materials. John Wiley \& Sons

Bestel M, Gawronski T, Abart R, Rhede D (2009) Compositional zoning of garnet porphyroblasts from the polymetamorphic Wölz Complex, Eastern Alps. Mineral Petrol 97:173-188. doi: 10.1007/s00710-0090084-z

Bestmann M, Habler G, Heidelbach F, Thoni M (2008) Dynamic recrystallization of garnet and related diffusion processes. J Struct Geol 30:777-790. doi: 10.1016/j.jsg.2008.02.007

Caddick MJ, Konopásek J, Thompson AB (2010) Preservation of Garnet Growth Zoning and the Duration of Prograde Metamorphism. J Petrol 51:2327-2347. doi: 10.1093/petrology/egq059

Carstens H (1971) Plastic stress relaxation around solid inclusions in pyrope. Contrib Mineral Petrol 32:289294. doi: 10.1007/BF00373346

Chakraborty S, Ganguly J (1991) Compositional Zoning and Cation Diffusion in Garnets. In: Ganguly J (ed) Diffus. At. Ordering Mass Transp. Springer US, pp 120-175

Cooke, O’Brien, Carswell (2000) Garnet zoning and the identification of equilibrium mineral compositions in high-pressure-temperature granulites from the Moldanubian Zone, Austria. J Metamorph Geol 18:551569.

Crone WC, Shield TW, Creuziger A, Henneman B (2004) Orientation dependence of the plastic slip near notches in ductile FCC single crystals. J Mech Phys Solids 52:85-112. doi: 10.1016/S00225096(03)00077-2

Danyushevsky LV, Sokolov S, Falloon TJ (2002) Melt inclusions in Olivine Phenocrysts: Using diffusive reequilibration to determine the cooling history of a crystal, with implications for the origin of Olivinephyric volcanic rocks. J Petrol 43:1651-1671.

De Ronde AA, Stünitz H, Tullis J, Heilbronner R (2005) Reaction-induced weakening of plagioclase-olivine composites. Tectonophysics 409:85-106. doi: 10.1016/j.tecto.2005.08.008

Erambert M, Austrheim H (1993) The effect of fluid and deformation on zoning and inclusion patterns in polymetamorphic garnets. Contrib Mineral Petrol 115:204-214. doi: 10.1007/BF00321220

Gaidies F, Capitani C, Abart R, Schuster R (2008) Prograde garnet growth along complex P-T-t paths: Results from numerical experiments on polyphase garnet from the Wölz Complex (Austroalpine basement). Contrib Mineral Petrol 155:673-688. doi: 10.1007/s00410-007-0264-y

Gourgues A-F (2002) Electron backscatter diffraction and cracking. Mater Sci Technol 18:119-133. doi: $10.1179 / 026708301125000320$ 
Gregurek D, Abart R, Hoinkes G (1997) Contrasting Eoalpine P-T evolutions in the southern Koralpe, Eastern Alps. Mineral Petrol 60:61-80.

Habler G, Thöni M (2001) Preservation of Permo-Triassic low-pressure assemblages in the Cretaceous highpressure metamorphic Saualpe crystalline basement (Eastern Alps, Austria). J Metamorph Geol 19:679-697. doi: 10.1046/j.0263-4929.2001.00338.x

Habler G, Thöni M, Miller C (2007) Major and trace element chemistry and Sm-Nd age correlation of magmatic pegmatite garnet overprinted by eclogite-facies metamorphism. Chem Geol 241:4-22. doi: 10.1016/j.chemgeo.2007.01.026

Hames WE, Menard T (1993) Fluid-assisted modification of garnet composition along rims, cracks, and mineral inclusion boundaries in samples of amphibolite facies schists. Am Mineral 78:338-344.

Hatert F, Baijot M, Philippo S, Wouters J (2010) Qingheiite-(Fe2+), Na2Fe2+MgAl(PO 4)3, a new phosphate mineral from the Sebastião Cristino pegmatite, Minas Gerais, Brazil. Eur J Mineral 22:459-467.

Heidelbach F, Terry MP, Bystricky M, et al. (2009) A simultaneous deformation and diffusion experiment: Quantifying the role of deformation in enhancing metamorphic reactions. Earth Planet Sci Lett 278:386-394. doi: 10.1016/j.eps1.2008.12.026

Hielscher R, Schaeben H, Siemes H (2010) Orientation distribution within a single hematite crystal. Math Geosci 42:359-375. doi: 10.1007/s11004-010-9271-z

Hwang SL, Shen P, Yui TF, Chu HT (2007) TiO2 nanoparticle trails in garnet: implications of inclusion pressure-induced microcracks and spontaneous metamorphic-reaction healing during exhumation. $\mathrm{J}$ Metamorph Geol 25:451-460. doi: 10.1111/j.1525-1314.2007.00705.x

Ji S, Martignole J (1994) Ductility of garnet as an indicator of extremely high temperature deformation. J Struct Geol 16:985-996. doi: 10.1016/0191-8141(94)90080-9

Keller LM, Abart R, Wirth R, et al. (2006) Enhanced mass transfer through short-circuit diffusion: Growth of garnet reaction rims at eclogite facies conditions. Am Mineral 91:1024-1038.

Konrad-Schmolke M, O’Brien PJ, Heidelbach F (2007) Compositional re-equilibration of garnet: the importance of sub-grain boundaries. Eur J Mineral 19:431-438. doi: 10.1127/0935-1221/2007/00191749

Ma Z, Shi N, Peng Z (1983) Crystal structure of a new phosphatic mineral - qingheiite. Sci Sin Ser B 26:876884.

Mancktelow NS, Pennacchioni G (2005) The control of precursor brittle fracture and fluid-rock interaction on the development of single and paired ductile shear zones. J Struct Geol 27:645-661. doi: 10.1016/j.jsg.2004.12.001

Martelat J-E, Malamoud K, Cordier P, et al. (2012) Garnet crystal plasticity in the continental crust, new example from south Madagascar. J Metamorph Geol 30:435-452. doi: 10.1111/j.15251314.2012.00974.x

Massey MA, Prior DJ, Moecher DP (2011) Microstructure and crystallographic preferred orientation of polycrystalline microgarnet aggregates developed during progressive creep, recovery, and grain boundary sliding. J Struct Geol 33:713-730. doi: 10.1016/j.jsg.2010.12.009

Miller C, Thöni M (1997) Eo-Alpine eclogitisation of Permian MORB-type gabbros in the Koralpe (Eastern Alps, Austria): New geochronological, geochemical and petrological data. Chem Geol 137:283-310.

Miller C, Thöni M, Konzett J, et al. (2005) Eclogites from the Koralpe and Saualpe type-localities, eastern Alps, Austria. Mitteilungen Österr Mineral Ges 227-263. 
Miller C, Zanetti A, Thöni M, Konzett J (2007) Eclogitisation of gabbroic rocks: Redistribution of trace elements and $\mathrm{Zr}$ in rutile thermometry in an Eo-Alpine subduction zone (Eastern Alps). Chem Geol 239:96-123. doi: 10.1016/j.chemgeo.2007.01.001

Moore P, lto J (1979) Alluaudites, wyllieites, arrojadites: crystal chemistry and nomenclature. Mineral Mag 43:227-235.

Morauf W (1982) Rb-Sr-and K-Ar-evidence for intensive alpidic influence of the paragneisses of Kor-and Saualpe, SE-Eastern Alps, Austria. TMPM Tschermaks Mineral Petrogr Mitteilungen 29:255-281. doi: 10.1007/BF01091796

Ohr SM (1985) An electron microscope study of crack tip deformation and its impact on the dislocation theory of fracture. Mater Sci Eng 72:1-35. doi: 10.1016/0025-5416(85)90064-3

Pippan R, Strobl G, Kreuzer H, Motz C (2004) Asymmetric crack wake plasticity - A reason for roughness induced crack closure. Acta Mater 52:4493-4502. doi: 10.1016/j.actamat.2004.06.014

Prior DJ, Wheeler J, Peruzzo L, et al. (2002) Some garnet microstructures: an illustration of the potential of orientation maps and misorientation analysis in microstructural studies. J Struct Geol 24:999-1011. doi: 10.1016/S0191-8141(01)00087-6

Rice JR, Thomson R (1974) Ductile versus brittle behaviour of crystals. Phil Mag 29:73-97.

Røhr TS, Austrheim H, Erambert M (2007) Stress-induced redistribution of yttrium and heavy rare-earth elements (HREE) in garnet during high-grade polymetamorphism. Am Mineral 92:1276-1287. doi: 10.2138/am.2007.2479

Ruoff AL, Balluffi RW (1963) Strain-Enhanced Diffusion in Metals. II. Dislocation and Grain-Boundary ShortCircuiting Models. J Appl Phys 34:1848-1853. doi: 10.1063/1.1729698

Schmid SM, Fügenschuh B, Kissling E, Schuster R (2004) Tectonic map and overall architecture of the Alpine orogen. Eclogae Geol Helvetiae 97:93-117. doi: 10.1007/s00015-004-1113-X

Storey CD, Prior DJ (2005) Plastic Deformation and Recrystallization of Garnet: A Mechanism to Facilitate Diffusion Creep. J Petrol 46:2593 -2613. doi: 10.1093/petrology/egi067

Stuwe K, Schuster R (2010) Initiation of subduction in the Alps: Continent or ocean? Geology 38:175-178. doi: 10.1130/G30528.1

Tenczer V, Powell R, Stüwe K (2006) Evolution of H2O content in a polymetamorphic terrane: the Plattengneiss Shear Zone (Koralpe, Austria). J Metamorph Geol 24:281-295. doi: 10.1111/j.15251314.2006.00637.x

Tenczer V, Stüwe K (2003) The metamorphic field gradient in the eclogite type locality, Koralpe region, Eastern Alps. J Metamorph Geol 21:377-393.

Terry MP, Heidelbach F (2006) Deformation-enhanced metamorphic reactions and the rheology of highpressure shear zones, Western Gneiss Region, Norway. J Metamorph Geol 24:3-18. doi: $10.1111 / \mathrm{j} .1525-1314.2005 .00618 . \mathrm{x}$

Thöni M (2006) Dating eclogite-facies metamorphism in the Eastern Alps - Approaches, results, interpretations: A review. Mineral Petrol 88:123-148.

Thöni M (2002) Sm-Nd isotope systematics in garnet from different lithologies (Eastern Alps): Age results, and an evaluation of potential problems for garnet Sm-Nd chronometry. Chem Geol 185:255-281. doi: 10.1016/S0009-2541(01)00410-7 
Thöni M, Miller C (2009) The "Permian event" in the Eastern European Alps: Sm-Nd and P-T data recorded by multi-stage garnet from the Plankogel unit. Chem Geol 260:20-36. doi:

10.1016/j.chemgeo.2008.11.017

Thöni M, Miller C (1996) Garnet Sm-Nd data from the Saualpe and the Koralpe (Eastern Alps, Austria): chronological and P-T constraints on the thermal and tectonic history. J Metamorph Geol 14:453-466. doi: $10.1046 / j .1525-1314.1996 .05995 . x$

Thöni M, Miller C, Zanetti A, et al. (2008) Sm-Nd isotope systematics of high-REE accessory minerals and major phases: ID-TIMS, LA-ICP-MS and EPMA data constrain multiple Permian-Triassic pegmatite emplacement in the Koralpe, Eastern Alps. Chem Geol 254:216-237.

Timms NE, Reddy SM, Fitz Gerald JD, et al. (2012) Inclusion-localised crystal-plasticity, dynamic porosity, and fast-diffusion pathway generation in zircon. J Struct Geol 35:78-89. doi: 10.1016/j.jsg.2011.11.005

Trepmann CA, Stöckhert B (2002) Cataclastic deformation of garnet: a record of synseismic loading and postseismic creep. J Struct Geol 24:1845-1856. doi: 10.1016/S0191-8141(02)00004-4

Tucker AT, Wilkinson AJ, Henderson MB, et al. (2000) Measurement of fatigue crack plastic zones in fine grained materials using electron backscattered diffraction. Mater Sci Technol 16:457-462. doi: $10.1179 / 026708300101507910$

Uğuz A, Martin JW (1996) Plastic zone size measurement techniques for metallic materials. Mater Charact 37:105-118. doi: 10.1016/S1044-5803(96)00074-5

Vernooij MGC, Kunze K, den Brok B (2006) "Brittle" shear zones in experimentally deformed quartz single crystals. J Struct Geol 28:1292-1306. doi: 10.1016/j.jsg.2006.03.018

Voegelé V, Ando JI, Cordier P, Liebermann RC (1998a) Plastic deformation of silicate garnets: I. High-pressure experiments. Phys Earth Planet Inter 108:305-318. doi: 10.1016/S0031-9201(98)00110-1

Voegelé V, Cordier P, Sautter V, et al. (1998b) Plastic deformation of silicate garnets: II. Deformation microstructures in natural samples. Phys Earth Planet Inter 108:319-338. doi: 10.1016/S00319201(98)00111-3

Vollbrecht A, Pawlowski J, Leiss B, et al. (2006) Ductile deformation of garnet in mylonitic gneisses from the Münchberg Massif (Germany). Tectonophysics 427:153-170. doi: 10.1016/j.tecto.2006.05.024

Whitney DL (1991) Calcium depletion halos and Fe-Mn-Mg zoning around faceted plagioclase inclusions in garnet from a high-grade pelitic gneiss. Am Mineral 76:493-500.

Whitney DL, Mechum TA, Dilek Y, Kuehner SM (1996) Modification of garnet by fluid infiltration during regional metamorphism in garnet through sillimanite-zone rocks, Dutchess County, New York. Am Mineral 81:696-705.

Whitney DL, Cooke ML, Frane SAD (2000) Modeling of radial microcracks at corners of inclusions in garnet using fracture mechanics. J Geophys Res 105:PP. 2843-2853. doi: 200010.1029/1999JB900375

Whitney DL, Evans BW (2010) Abbreviations for names of rock-forming minerals. Am Mineral 95:185-187. doi: $10.2138 / \mathrm{am} .2010 .3371$

Wilkinson AJ, Meaden G, Dingley DJ (2006) High resolution mapping of strains and rotations using electron backscatter diffraction. Mater Sci Technol 22:1271-1278. doi: 10.1179/174328406X130966 


\section{Figure 1}

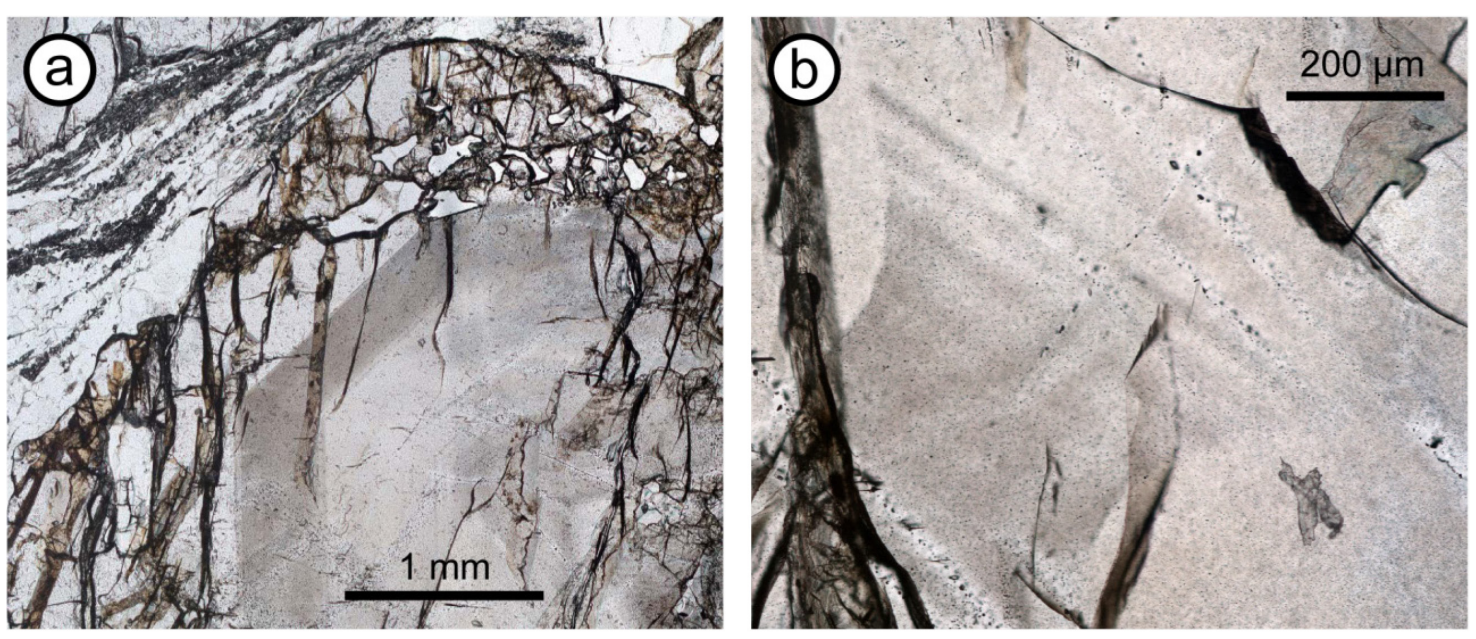

Fig. 1 Photomicrographs of inclusion-rich garnets from the Wirtbartl locality. Varying inclusion abundance is reflected by color variations defining $\mathbf{a}$ concentric and $\mathbf{b}$ sector zoning. Trails of inclusions crosscutting the sector zoning are shown in $\mathbf{b}$

\section{Figure 2}

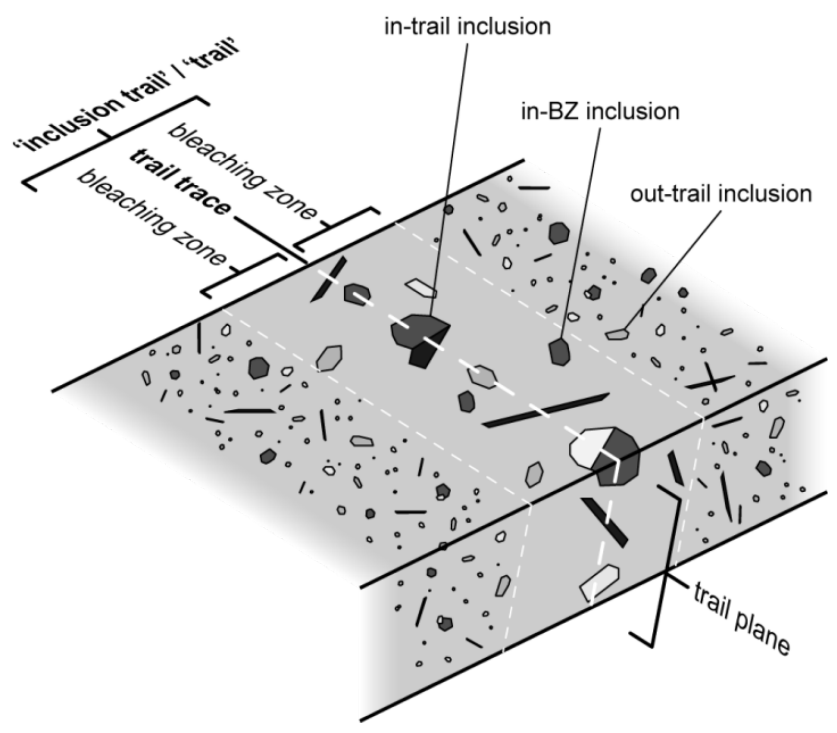

Fig. 2 Idealized sketch of the inclusion trail microstructure labeled with the definitions used in this paper 
Figure 3
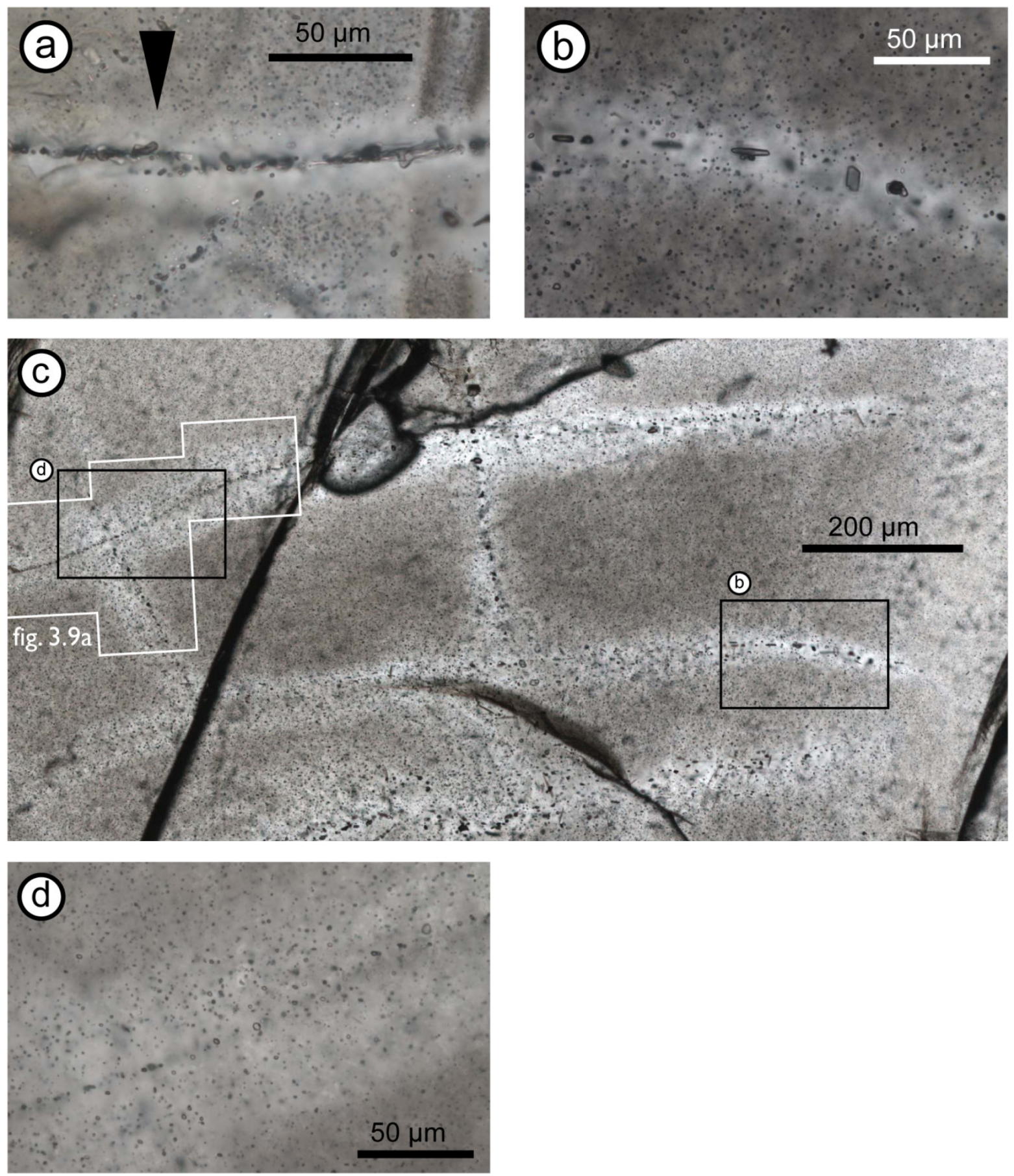

Fig. 3 Photomicrographs of the inclusion trail microstructure. a Two inclusion trails terminate offset from each other with an en-echelon overlap (black arrow). b Inclusion trail with a bleaching zone almost free of inclusions, located in domain KII. c The area of intersecting trails in domain KII, with the sites of close up images, element mapping and EBSD mapping indicated. $\mathbf{d}$ A fainter trail with a broader bleaching zone still containing some inclusions, domain KII 
Figure 4

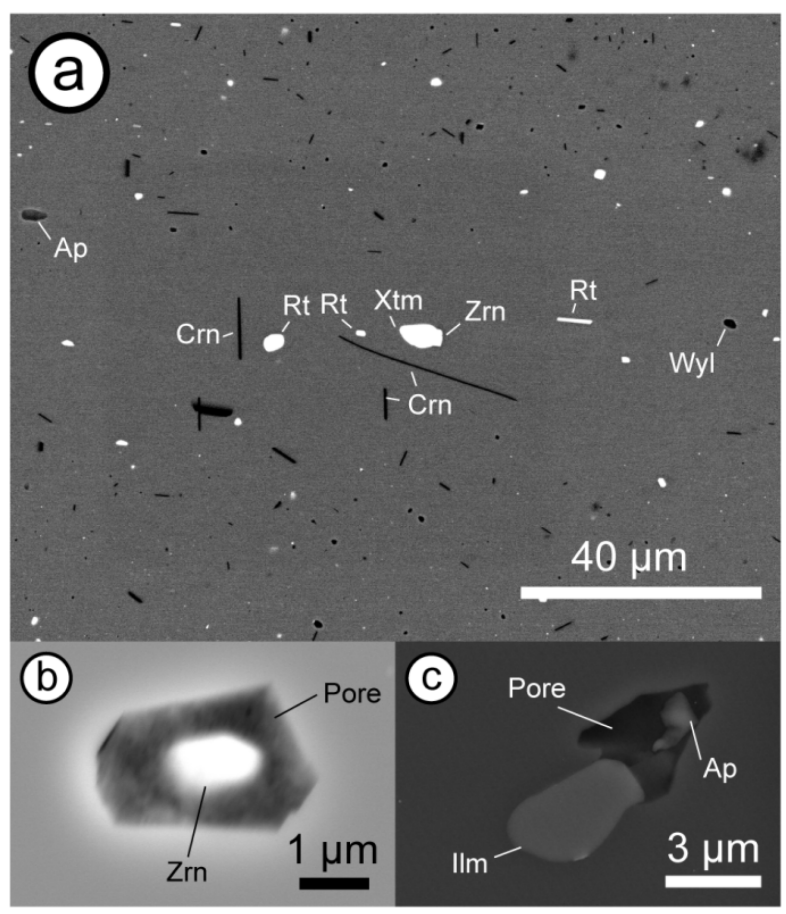

Fig. 4 a Backscattered electron image of an inclusion trail in domain KII annotated with phase IDs from EDS spectra, Wyl = wyllieite group phosphate. $\mathbf{b}+\mathbf{c}$ Secondary electron images of pores and associated crystals, both within trails in domain KVK 
Figure 5
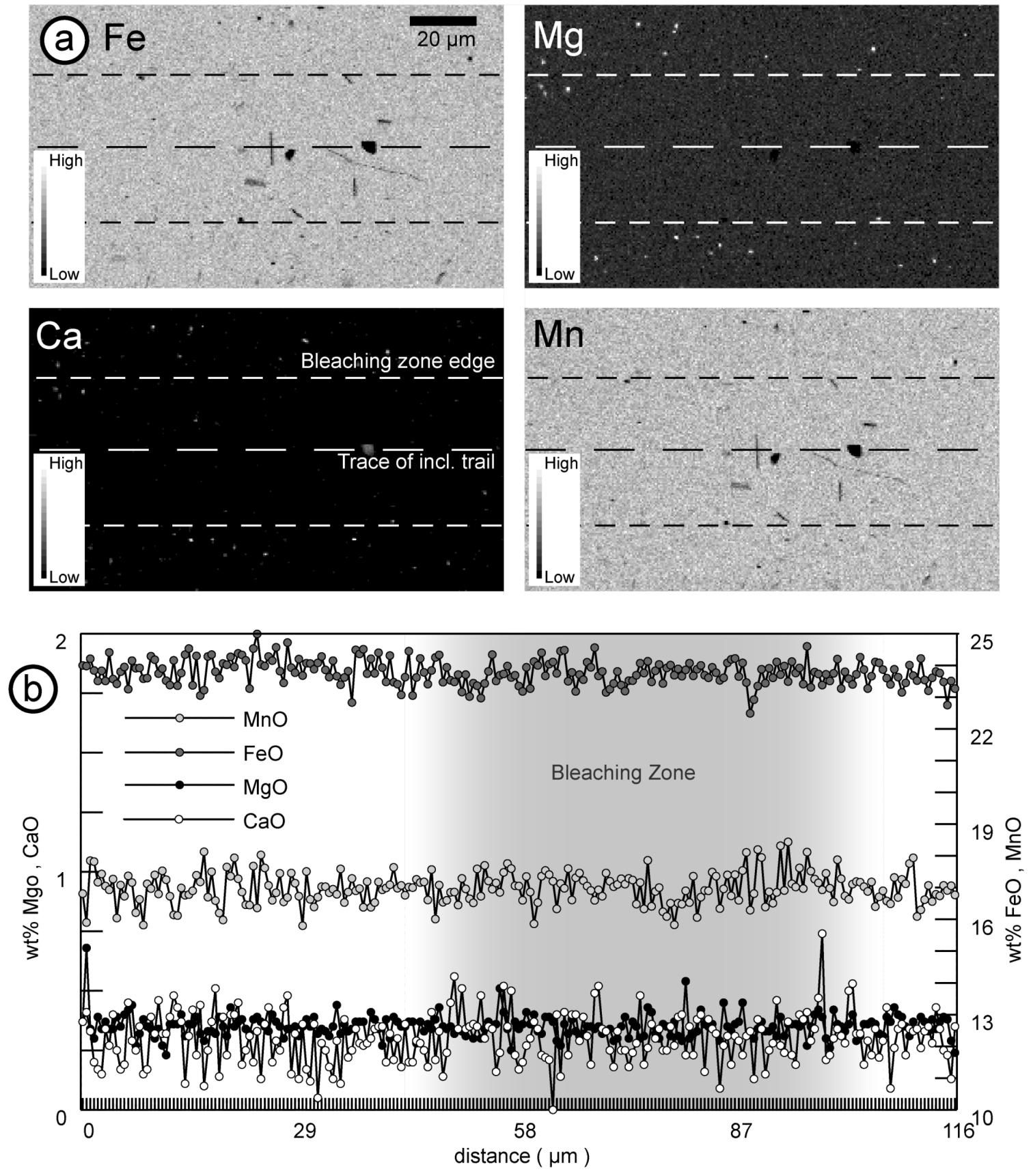

Fig. 5 a Element distribution map across a trail in domain KII (see fig. 3c for location) showing a homogeneous garnet composition. Locations of the bleaching zone and central trail are indicated. b A quantitative compositional profile across a bleaching zone in domain KVK (see figs. $7 \mathrm{a}+\mathrm{b}$ for location) acquired at $6 \mathrm{kV}$ accelerating voltage. 


\section{Figure 6}
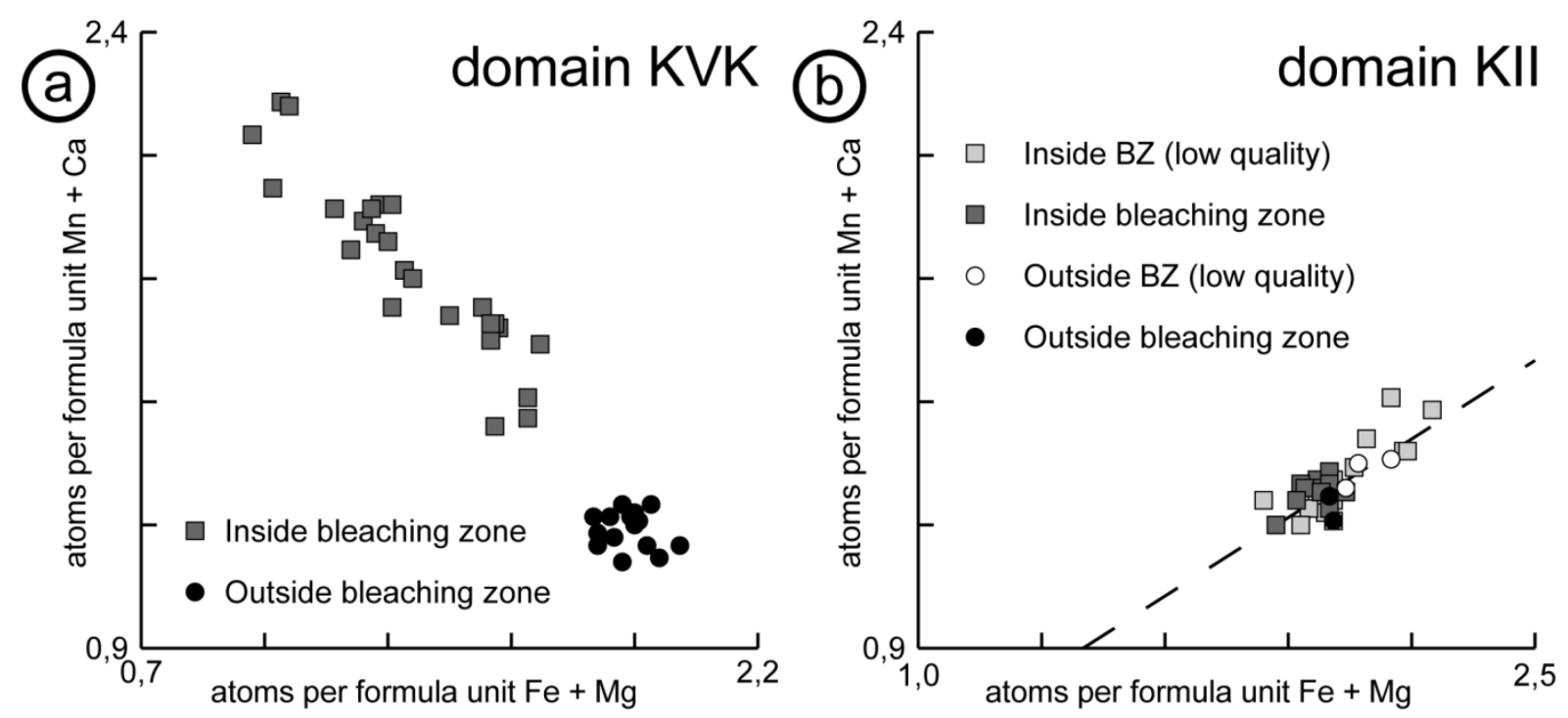

Fig. 6 Plots of atoms per formula unit $\mathrm{Fe}+\mathrm{Mg}$ vs $\mathrm{Mn}+\mathrm{Ca}$ in wyllieite group phosphates, comparing inclusions located inside and outside bleaching zones. a In domain KVK, inclusions inside bleaching zones have altered and variable compositions relative to out-trail inclusions. b In domain KII, inclusion composition does not differ between the two microstructural settings. Points with totals $>106 \mathrm{wt} \%$ and/or $\mathrm{SiO}_{2}$ contents $>1 \mathrm{wt} \%$ are labeled as 'low quality' data. Spread in the data is along a line $(\mathrm{Mn}+\mathrm{Ca}) /(\mathrm{Fe}+\mathrm{Mg})=0.64$ (plotted as a dashed line) and is an analytical artefact 
Figure 7
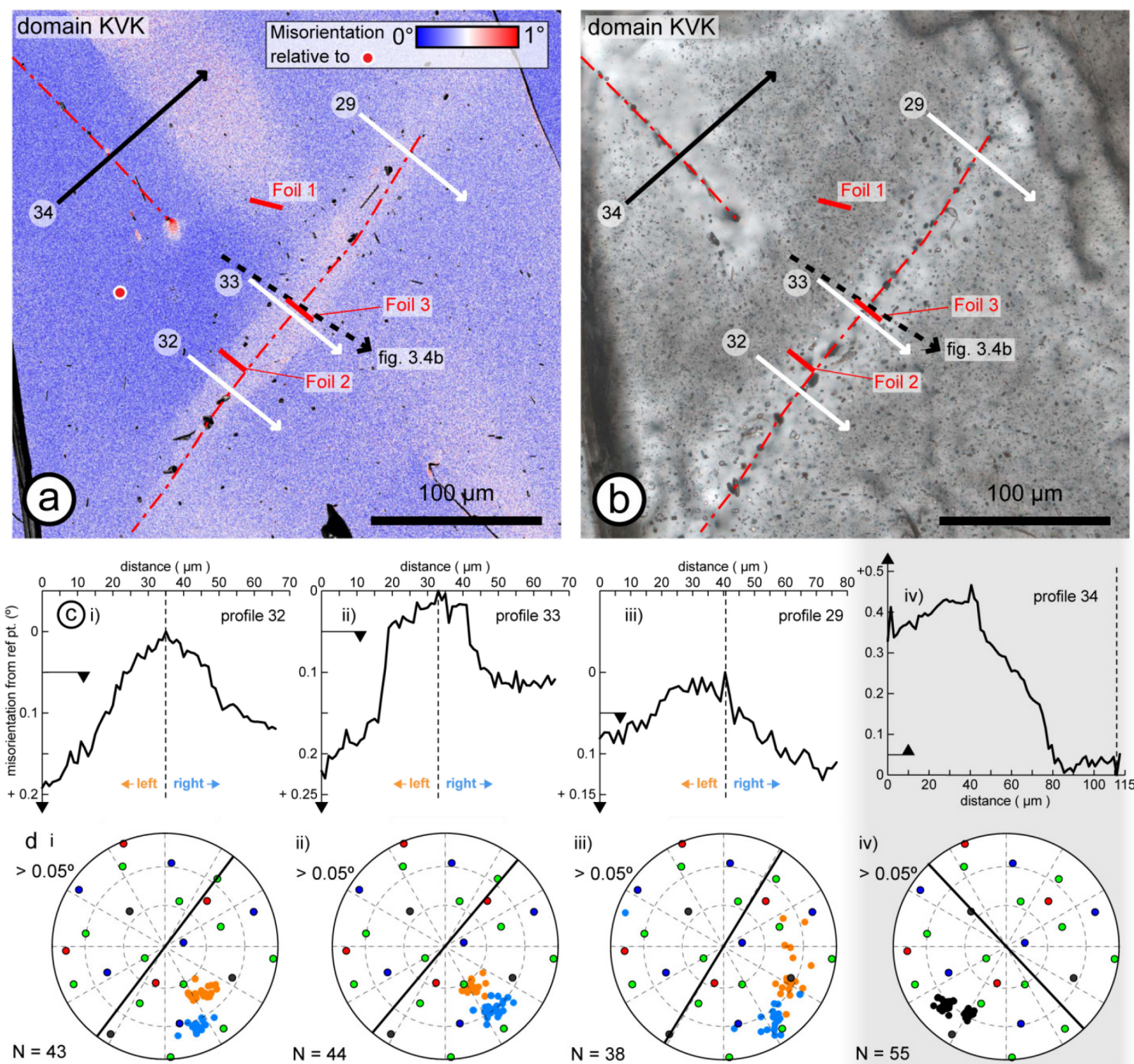

Fig. 7 a EBSD map of part of domain KVK, shown as thin section photograph in $\mathbf{b}$. The map is color coded for relative misorientation angle to a reference point. Locations of the compositional profile (fig. 5b), EBSD cross correlation profiles (c) and TEM foils (fig. 8a-e, g) are marked. c Profiles of misorientation angle to a reference point (near the start of each profile) with distance across the microstructure, obtained using cross correlation. Arrows at the left indicate the threshold misorientation angle below which misorientation axes are not plotted. d Antipodal, upper hemisphere, equal area plots of misorientation axes for misorientations above the specified threshold misorientation angle, color coded for the density of misorientation axes. The thick line indicates the trace orientation of the trail where it cuts each profile. Garnet directions are plotted as colored circles for $<100>$ (black), $<110>$ (blue), $<111>$ (red) and $<112>$ (green) 


\section{Figure 8}

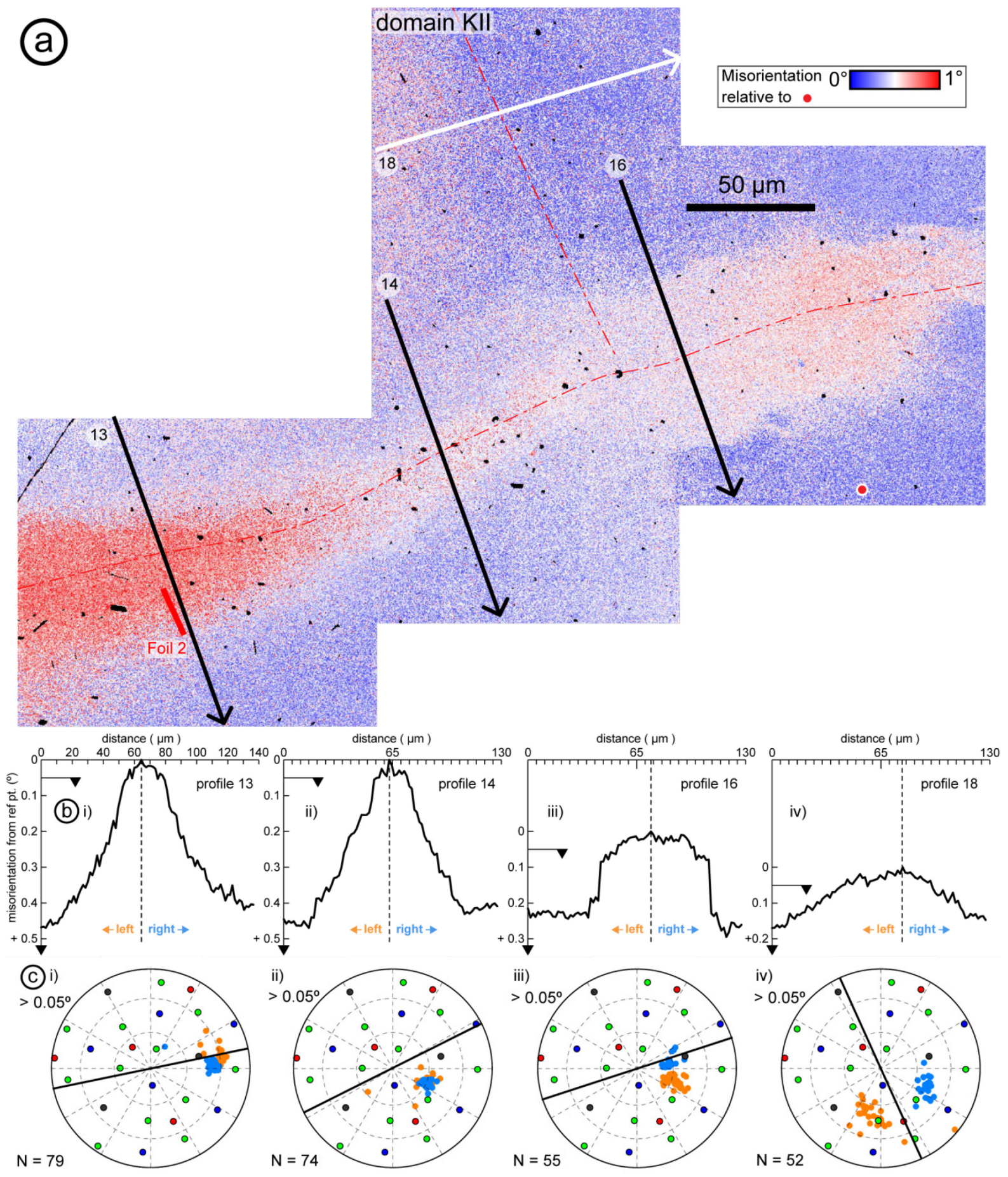

Fig. 8 a EBSD map of part of domain KII, shown as thin section photograph in fig. 3c. The map is color coded for relative misorientation angle to a reference point. Locations of the EBSD cross correlation profiles (b) and TEM foil (fig. $9 \mathrm{f}+\mathrm{h}$ ) are marked. b Profiles of misorientation angle to a reference point (near the start of each profile) with distance across the microstructure, obtained using cross correlation. Arrows at the left indicate the threshold misorientation angle below which misorientation axes are not plotted. $\mathbf{c}$ Antipodal, upper hemisphere, 
equal area plots of misorientation axes for misorientations above the specified threshold misorientation angle, color coded for the density of misorientation axes. The thick line indicates the trace orientation of the trail where it cuts each profile. Garnet directions are plotted as colored circles for $<100>$ (black), $<110>$ (blue), $<111>$ (red) and $<112>$ (green)

\section{Figure 9}
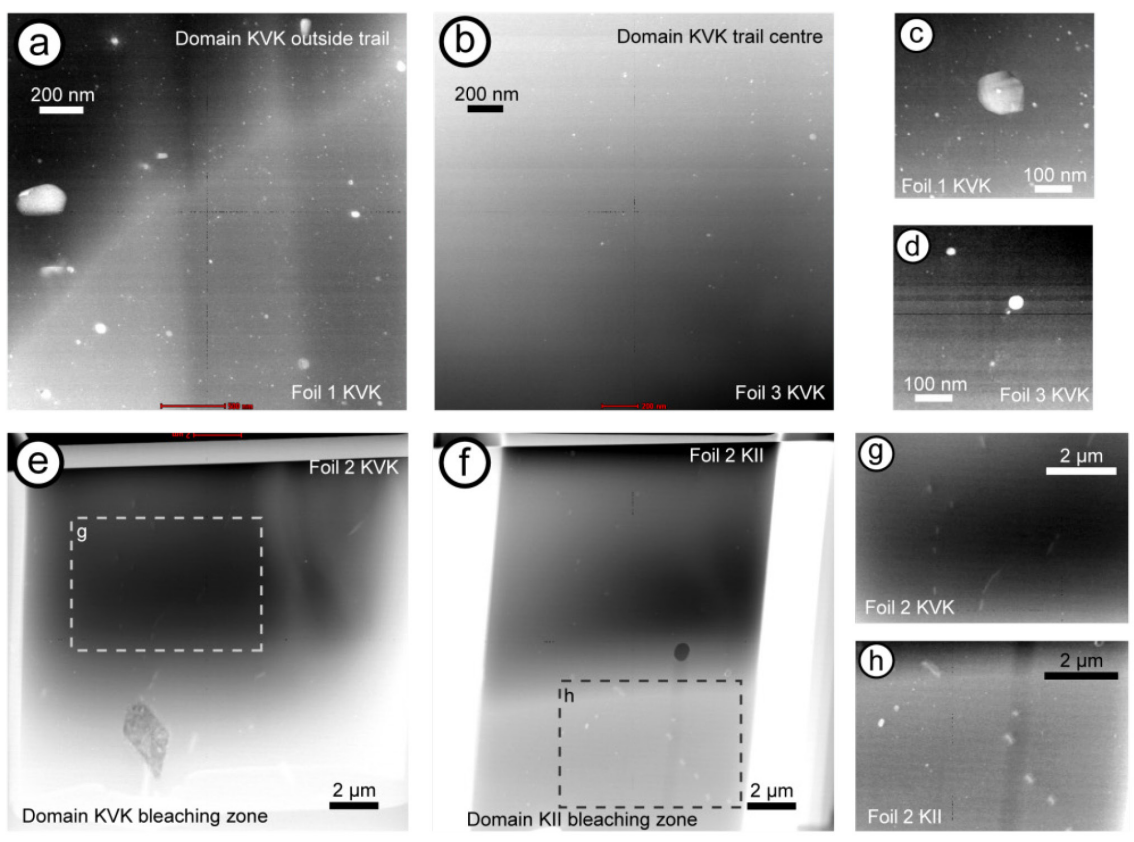

Fig. 9 Scanning mode (STEM) HAADF images in TEM (foil locations in figs. 7a+b and fig. 8a). All images were taken at working distances of $220-330 \mathrm{~mm}$, thus brightness variations are a combination of orientation contrast, foil thickness and Z number variation. a STEM micrograph of a foil from outside trails, domain KVK. When compared with $\mathbf{b}$, a foil from the center of a trail, a marked contrast in the abundance of inclusions from $100 \mathrm{~nm}-\sim 1 \mu \mathrm{m}$ is seen. $\mathbf{c}$ Higher magnification STEM image from the same out-trail foil as a, showing the presence of inclusions both $>$ and $<100 \mathrm{~nm}$. d Higher magnification from the same in-trail foil as $\mathbf{b}$, showing continued presence of inclusions $<100 \mathrm{~nm}$. e Foil from within bleaching zone, domain KVK. Scattered dislocations are present, though difficult to observe due to varying contrast. f Foil from within bleaching zone, domain KII. Scattered dislocations are present, though difficult to observe due to thickness variation contrast. $\mathbf{g}$

$+\mathbf{h}$ Enlargements of images from $\mathbf{e}+\mathbf{f}$ respectively, with enhanced contrast to show dislocation shapes and distribution 
Table 1

\begin{tabular}{|c|c|c|c|c|}
\hline Phase & Idealised composition & $\begin{array}{l}\text { Minor } \\
\text { elements }\end{array}$ & $\begin{array}{l}\text { Shape (as isolated } \\
\text { inclusion) }\end{array}$ & Notes \\
\hline Corundum & $\mathrm{Al}_{2} \mathrm{O}_{3}$ & - & Tabular & $\begin{array}{l}\text { Smallest dimension } \\
\text { often }<<500 \mathrm{~nm}\end{array}$ \\
\hline Rutile & $\mathrm{TiO}_{2}$ & $\begin{array}{l}\mathrm{Fe}^{3+}, \mathrm{Sn} \\
\mathrm{Nb}, \mathrm{Ta}\end{array}$ & Needle-like & $\begin{array}{l}\text { Can exhibit shape } \\
\text { preferred orientation }\end{array}$ \\
\hline Ilmenite & $\mathrm{FeTiO}_{3}$ & $\mathrm{Mn}, \mathrm{Fe}^{3+}$ & Needle-like & - \\
\hline Zircon & $\mathrm{ZrSiO}_{4}$ & - & - & $\begin{array}{l}\text { Almost always part of } \\
\text { multiphase inclusion }\end{array}$ \\
\hline Xenotime & $\mathrm{YPO}_{4}$ & REE & Slightly elongate & - \\
\hline Apatite & $\mathrm{Ca}_{5}\left(\mathrm{PO}_{4}\right)_{3}(\mathrm{OH}, \mathrm{F})$ & - & Approx. equant & $\begin{array}{l}\text { Very rare outside } \\
\text { trails }\end{array}$ \\
\hline $\begin{array}{l}\text { Wyllieite gp. } \\
\text { phosphate }\end{array}$ & $(\mathrm{Na}, \mathrm{Ca}, \mathrm{Mn})_{2}(\mathrm{Mn}, \mathrm{Fe})(\mathrm{Fe}, \mathrm{Mg}) \mathrm{Al}\left(\mathrm{PO}_{4}\right)_{3}$ & - & Approx. equant & $\begin{array}{l}\text { Sub-rounded crystal } \\
\text { faces }\end{array}$ \\
\hline
\end{tabular}

Table 1 List of phases found as inclusions in garnet both inside and outside the inclusion trail microstructure 
Table 2

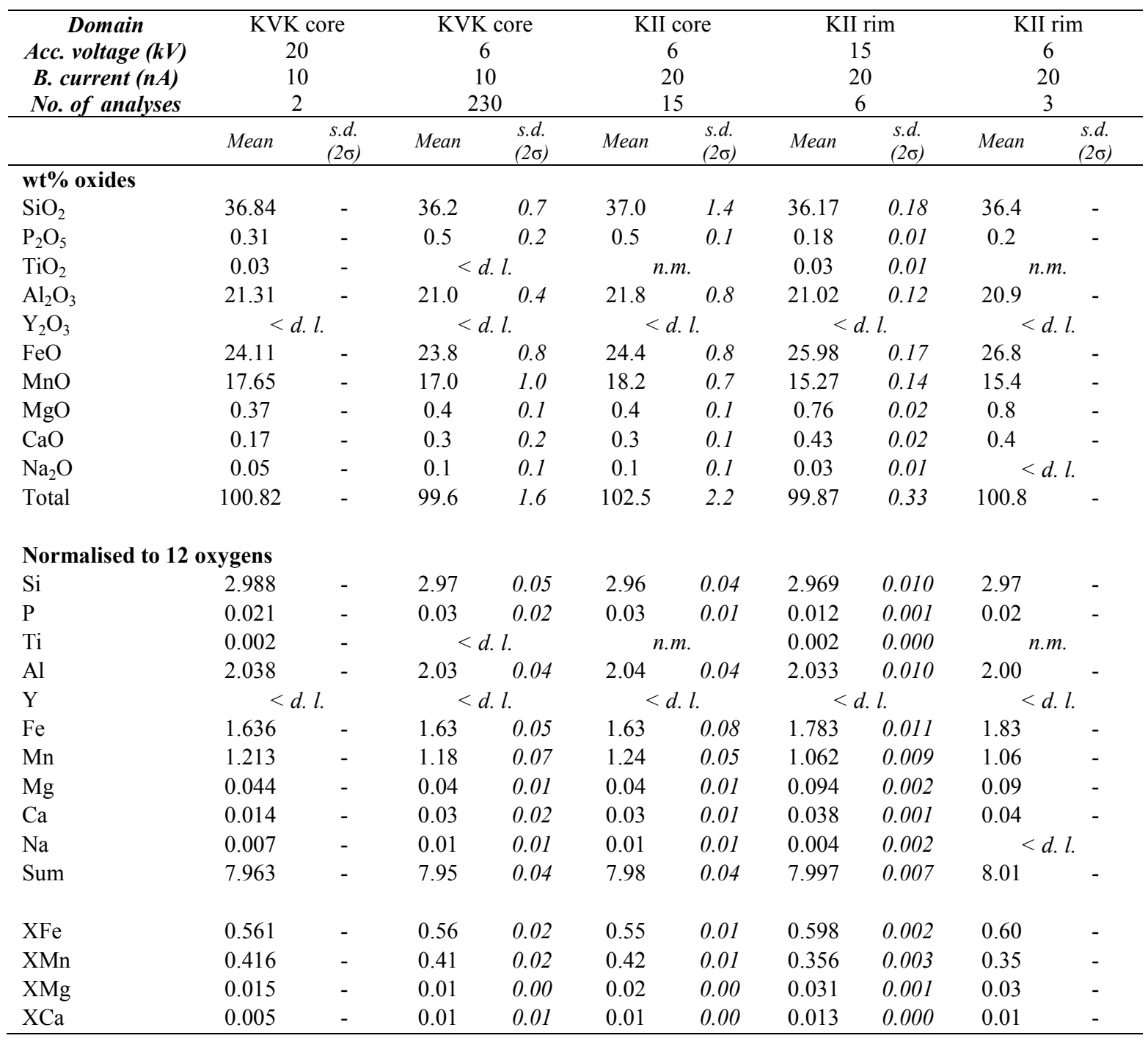

Table 2 Mean compositions with standard deviations for garnet at high and low accelerating voltage in the two domains examined in detail. n.m. indicates an element was not measured for a particular set of data. $<d$. $l$. indicates the measured value was below the detection limit 
Table 3

\begin{tabular}{|c|c|c|c|c|c|c|}
\hline $\begin{array}{c}\text { Domain } \\
\text { Inclusion } \\
\text { type }\end{array}$ & \multicolumn{2}{|c|}{$\begin{array}{c}\text { Out-trail } \\
\text { inclusions. }\end{array}$} & \multicolumn{2}{|c|}{$\begin{array}{c}\text { KII } \\
\text { Out-trail } \\
\text { inclusions } \\
\text { (lowest Si } \\
\text { content) }\end{array}$} & \multicolumn{2}{|c|}{$\begin{array}{c}\text { KII } \\
\text { All inclusions } \\
\text { (both inside } \\
\text { \& outside } \\
\text { trails) }\end{array}$} \\
\hline $\begin{array}{c}\text { No. of } \\
\text { analyses }\end{array}$ & \multicolumn{2}{|c|}{15} & \multicolumn{2}{|c|}{2} & \multicolumn{2}{|c|}{22} \\
\hline $\begin{array}{c}\text { Current } \\
(n A)\end{array}$ & \multicolumn{2}{|c|}{20} & \multicolumn{2}{|c|}{10} & \multicolumn{2}{|c|}{10} \\
\hline & Mean & $\begin{array}{l}\text { s.d. } \\
(2 \sigma) \\
\end{array}$ & Mean & $\begin{array}{l}s . d . \\
(2 \sigma)\end{array}$ & Mean & $\begin{array}{l}\text { s.d. } \\
(2 \sigma)\end{array}$ \\
\hline \multicolumn{7}{|c|}{ wt $\%$ oxides } \\
\hline $\mathrm{P}_{2} \mathrm{O}_{5}$ & 44.9 & 2.2 & 45.6 & - & 45.5 & 2.9 \\
\hline $\mathrm{SiO}_{2}$ & 0.8 & 0.2 & 0.9 & - & 0.8 & 0.2 \\
\hline $\mathrm{TiO}_{2}$ & \multicolumn{2}{|c|}{$<d . l$. } & \multicolumn{2}{|c|}{ n.m. } & \multicolumn{2}{|c|}{ n.m. } \\
\hline $\mathrm{Al}_{2} \mathrm{O}_{3}$ & 6.7 & 0.8 & 6.2 & - & 6.7 & 0.7 \\
\hline $\mathrm{Y}_{2} \mathrm{O}_{3}$ & \multicolumn{2}{|c|}{$<d . l}$. & \multicolumn{2}{|c|}{$<$ d. $l}$. & \multicolumn{2}{|c|}{$<d . l}$. \\
\hline $\mathrm{MgO}$ & 5.8 & 0.8 & 6.4 & - & 5.9 & 0.7 \\
\hline $\mathrm{FeO}$ & 19.2 & 1.6 & 17.6 & - & 18.8 & 2.8 \\
\hline $\mathrm{MnO}$ & 14.5 & 1.2 & 14.6 & - & 15.3 & 1.1 \\
\hline $\mathrm{CaO}$ & 3.1 & 0.3 & 4.0 & - & 3.9 & 0.6 \\
\hline $\mathrm{Na}_{2} \mathrm{O}$ & 8.0 & 0.7 & 7.8 & - & 7.9 & 0.7 \\
\hline Total & 103.1 & 2.9 & 103.2 & - & 104.9 & 4.5 \\
\hline \multicolumn{7}{|c|}{ Normalised to 12 oxygens } \\
\hline $\mathrm{P}$ & 2.91 & 0.08 & 2.89 & - & 2.87 & 0.08 \\
\hline $\mathrm{Si}$ & 0.06 & 0.02 & 0.07 & - & 0.06 & 0.02 \\
\hline $\mathrm{Ti}$ & \multicolumn{2}{|c|}{$<d . l$} & \multicolumn{2}{|c|}{ n.m. } & \multicolumn{2}{|c|}{ n.m. } \\
\hline $\mathrm{Al}$ & 0.61 & 0.07 & 0.55 & - & 0.59 & 0.06 \\
\hline $\mathrm{Y}$ & \multicolumn{2}{|c|}{$<d . l$. } & \multicolumn{2}{|c|}{$<d . l$. } & \multicolumn{2}{|c|}{$<$ d. $l$} \\
\hline $\mathrm{Mg}$ & 0.66 & 0.09 & 0.71 & - & 0.66 & 0.10 \\
\hline $\mathrm{Fe}$ & 1.23 & 0.10 & 1.30 & - & 1.32 & 0.07 \\
\hline $\mathrm{Mn}$ & 0.94 & 0.07 & 0.92 & - & 0.96 & 0.06 \\
\hline $\mathrm{Ca}$ & 0.25 & 0.03 & 0.32 & - & 0.31 & 0.05 \\
\hline $\mathrm{Na}$ & 1.19 & 0.09 & 1.14 & - & 1.14 & 0.08 \\
\hline $\begin{array}{l}\square \\
\text { calculated }\end{array}$ & 0.14 & 0.11 & 0.10 & - & 0.09 & 0.10 \\
\hline Sum & 8.00 & - & 8.00 & - & 8.00 & - \\
\hline $\begin{array}{l}\mathrm{Mn} / \\
(\mathrm{Mn}+\mathrm{Fe})\end{array}$ & 0.43 & 0.03 & 0.42 & - & 0.42 & 0.02 \\
\hline $\begin{array}{l}\mathrm{Ca} / \\
(\mathrm{Ca}+\mathrm{Mg})\end{array}$ & 0.28 & 0.03 & 0.31 & - & 0.32 & 0.03 \\
\hline
\end{tabular}

Table 3 Mean compositions with standard deviations for wyllieite group phosphate outside trails in domain $\mathrm{KVK}$ and the mean composition of all wyllieite group phosphates in domain KII regardless of location (as composition does not vary in this domain). n.m. indicates an element was not measured for a particular set of data. $<d$. $l$. indicates the measured value was below the detection limit 


\section{Online Resource 1}

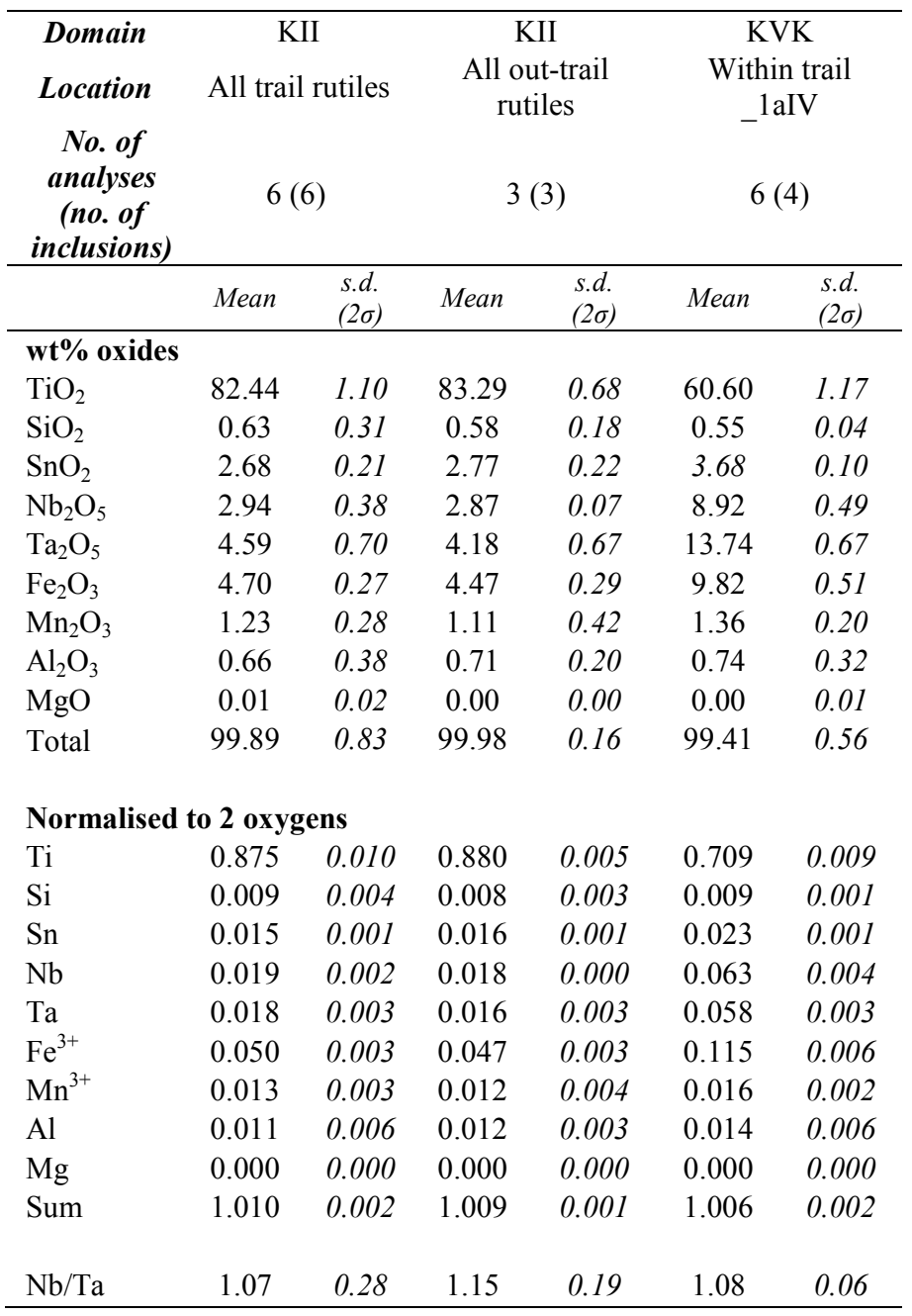

Online Resource 1 Table of mean compositions with standard deviations for rutile grains inside and outside trails in domain KII, and for rutile within one trail in domain KVK 


\section{Online Resource 2}

\begin{tabular}{|c|c|c|c|c|c|c|}
\hline \multirow[t]{2}{*}{$\begin{array}{c}\text { Domain } \\
\text { Location } \\
\text { No. of } \\
\text { analyses } \\
\text { (no. of } \\
\text { inclusions) } \\
\end{array}$} & \multicolumn{2}{|c|}{$\begin{array}{c}\text { KVK } \\
\text { Within trail } \\
\text { _ } 1 \text { aIV }\end{array}$} & \multicolumn{2}{|c|}{$\begin{array}{c}\text { KVK } \\
\text { Within trail } \\
\quad 1 \text { aII }\end{array}$} & \multicolumn{2}{|c|}{$\begin{array}{c}\text { KVK } \\
\text { Within trail } \\
\ldots 1 \mathrm{aV}\end{array}$} \\
\hline & Mean & $\begin{array}{l}s . d . \\
(2 \sigma) \\
\end{array}$ & Mean & $\begin{array}{l}s . d . \\
(2 \sigma)\end{array}$ & Mean & $\begin{array}{l}\text { s.d. } \\
(2 \sigma)\end{array}$ \\
\hline \multicolumn{7}{|l|}{ wt\% oxides } \\
\hline $\mathrm{TiO}_{2}$ & 48.48 & 1.06 & 48.63 & - & 48.14 & - \\
\hline $\mathrm{SiO}_{2}$ & 0.48 & 0.06 & 0.68 & - & 0.49 & - \\
\hline $\mathrm{SnO}_{2}$ & 0.03 & 0.07 & 0.10 & - & 0.06 & - \\
\hline $\mathrm{Nb}_{2} \mathrm{O}_{5}$ & 0.36 & 0.12 & 0.27 & - & 0.21 & - \\
\hline $\mathrm{Ta}_{2} \mathrm{O}_{5}$ & 0.36 & 0.08 & 0.17 & - & 0.22 & - \\
\hline $\mathrm{Fe}_{2} \mathrm{O}_{3}$ & 5.63 & 1.81 & 4.46 & - & 6.59 & - \\
\hline $\mathrm{Al}_{2} \mathrm{O}_{3}$ & 0.30 & 0.07 & 0.34 & - & 0.32 & - \\
\hline $\mathrm{FeO}$ & 35.16 & 1.12 & 33.74 & - & 32.35 & - \\
\hline $\mathrm{MnO}$ & 9.52 & 0.80 & 11.13 & - & 11.79 & - \\
\hline $\mathrm{MgO}$ & 0.01 & 0.01 & 0.00 & - & 0.01 & - \\
\hline Total & 100.32 & 1.13 & 99.52 & - & 100.18 & - \\
\hline \multicolumn{7}{|c|}{ Normalised to 3 oxygens } \\
\hline $\mathrm{Ti}$ & 0.920 & 0.020 & 0.928 & - & 0.914 & - \\
\hline $\mathrm{Si}$ & 0.012 & 0.002 & 0.017 & - & 0.013 & - \\
\hline $\mathrm{Sn}$ & 0.000 & 0.001 & 0.001 & - & 0.001 & - \\
\hline $\mathrm{Nb}$ & 0.004 & 0.001 & 0.003 & - & 0.002 & - \\
\hline $\mathrm{Ta}$ & 0.002 & 0.001 & 0.001 & - & 0.002 & - \\
\hline $\mathrm{Fe}^{3+}$ & 0.107 & 0.034 & 0.085 & - & 0.125 & - \\
\hline $\mathrm{Al}$ & 0.009 & 0.002 & 0.010 & - & 0.009 & - \\
\hline $\mathrm{Fe}^{2+}$ & 0.742 & 0.022 & 0.715 & - & 0.683 & - \\
\hline $\mathrm{Mn}$ & 0.203 & 0.018 & 0.239 & - & 0.252 & - \\
\hline $\mathrm{Mg}$ & 0.000 & 0.000 & 0.000 & - & 0.000 & - \\
\hline Sum & 2.000 & 0.000 & 2.000 & - & 2.000 & - \\
\hline XIlmenite & 0.74 & 0.02 & 0.72 & - & 0.68 & - \\
\hline XPyrophanite & 0.20 & 0.02 & 0.24 & - & 0.25 & - \\
\hline XHaematite & 0.05 & 0.02 & 0.04 & - & 0.06 & - \\
\hline
\end{tabular}

Online Resource 2 Table of mean compositions with standard deviations for ilmenite within three different trails of domain KVK 


\section{Online Resource 3}
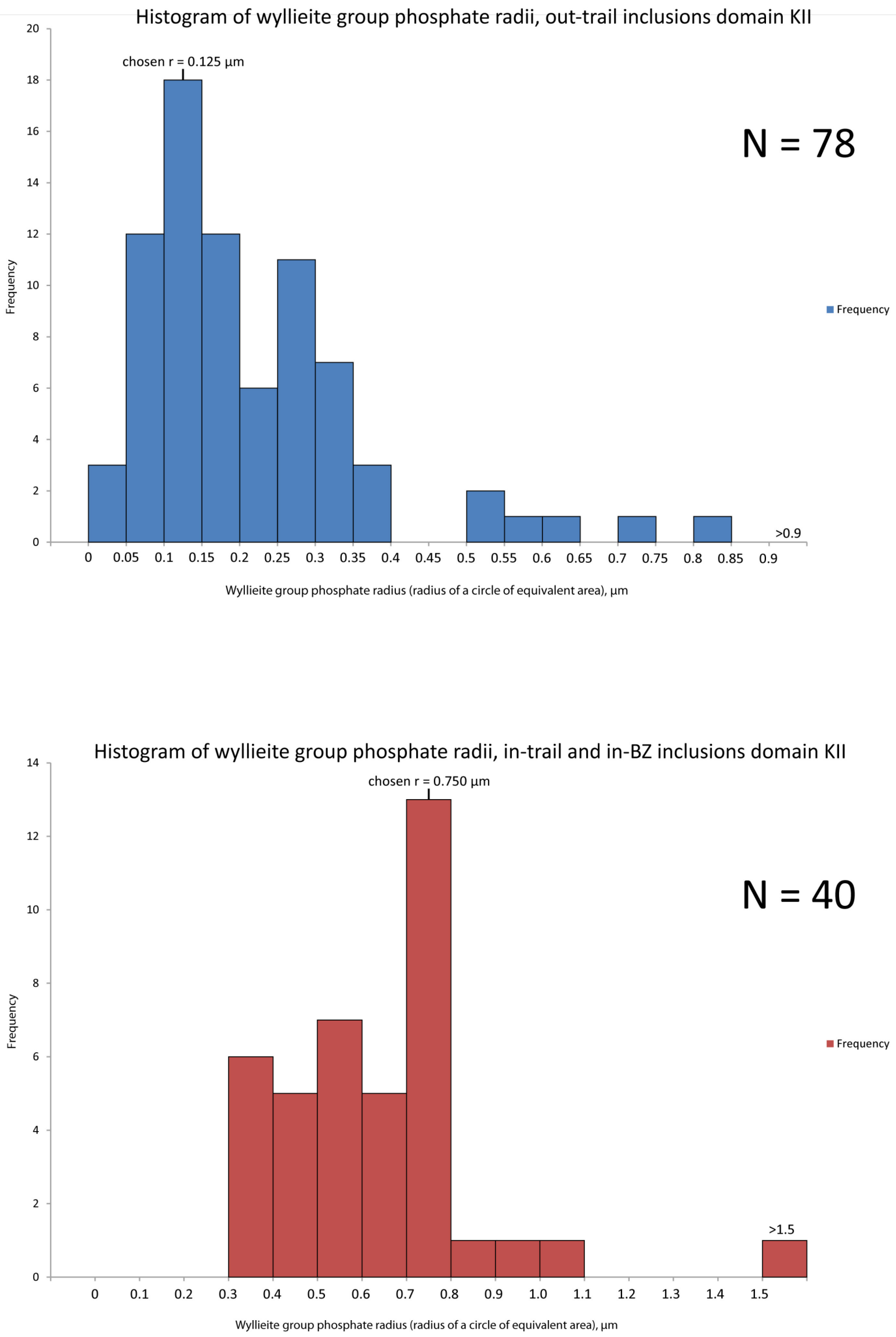

The final publication is available at Springer via http://dx.doi.org/10.1007/s00410-014-1077-4 
Online resource 3 Histograms showing the frequency distribution of the radii of wyllieite group phosphate inclusions in domain KII. Radii were calculated as the radius of a circle with equivalent area to the ellipse manually drawn around each inclusion on BSE images. Out-trail inclusions in a, in-trail and in-BZ inclusions in b. The values chosen as representing the 'mean radius' $<R>$ of each population are marked 